ANUARIO DE ESTUDIOS MEDIEVALES

49/1, enero-junio de 2019, pp. 137-169

ISSN 0066-5061

https://doi.org/10.3989/aem.2019.49.1.05

\title{
MODELOS DE TRANSMISIÓN TEXTUAL DE LOS SERMONES DE SAN VICENTE FERRER: LA TRADICIÓN MANUSCRITA
}

\author{
MODELS OF TEXTUAL TRANSMISSION OF SAINT VINCENT FERRER'S \\ SERMONS: THE MANUSCRIPT TRADITION
}

FRANCISCO M. GIMENO BLAY

Universitat de València

http://orcid.org/0000-0002-4883-2960

\begin{abstract}
Resumen: El presente artículo se propone reconstruir el proceso de escrituración de los sermones predicados por Vicente Ferrer. En la tradición textual manuscrita se pueden distinguir: las colecciones de esquemas y las que transcriben los sermones in extenso, fruto de la reelaboración de las notas tomadas por los reportadores. Se estudia, asimismo, el contenido literario de algunos manuscritos, aquellos en los que se propone la edición para todo el año como la redacción tolosana, con los volúmenes de tempore y de sanctis, o las colecciones dedicadas a un tiempo litúrgico determinado; se incluyen igualmente otros manuscritos que presentan series derivadas de algunas campañas de predicación.
\end{abstract}

Palabras clave: Vicent Ferrer; manuscritos de esquemas; manuscritos de sermones; reportadores; crítica textual.

Abstract: The aim of the present article is to reconstruct the writing process of the sermons preached by Vincent Ferrer. In the manuscript textual tradition, one can identify: the collections of schemas and the collections that transcribe the sermons in extenso, which are the result of reworking the notes taken by the reportatores. Moreover, the literary content of some manuscripts is studied, including those in which an annual edition is proposed, such as the Tolosan redaction, with its de tempore and de sanctis volumes, or the collections dedicated to a specific liturgical moment. Further manuscripts presenting series derived from some preaching campaigns are also featured in the article.

Keywords: Vicent Ferrer; manuscripts of schemas; manuscripts of sermons, reportatores; textual criticism.

\section{SUMARIO}

1. Escribir sermones.- 1.1. Manuscritos de esquemas.- 1.2. Libri reportationum.1.3. Manuscrito de reportador.- 1.4. ... in sexternis sequentibus propia manu conscripsi.- 1.5. Antonio Anglada y el manuscrito de Aviñón.- 2. ¿Quiénes escribían?.3. Organización temática de las reportationes.- 3.1. Reportationes per circuli annum.- 3.2. Sermones de sanctis.- 3.3. Sermones quadragesimales.- 4. Manuscritos copiados post mortem. Dos testimonios datados.- 5. Bibliografía citada.

\section{ESCRIBIR SERMONES}

No se conoce suficientemente el proceso de escrituración de los sermones del maestro Vicente Ferrer, tal vez porque no se ha estudiado

\footnotetext{
Citation / Cómo citar este artículo: Gimeno Blay, Francisco M. (2019), Modelos de transmisión textual de los sermones de San Vicente Ferrer: la tradición manuscrita, "Anuario de Estudios Medievales" 49/1, pp. 137-169. https:// doi.org/10.3989/aem.2019.49.1.05

Copyright: (C) 2019 CSIC. Este es un artículo de acceso abierto distribuido bajo los términos de la licencia de uso y distribución Creative Commons Reconocimiento 4.0 Internacional (CC BY 4.0).
} 
convenientemente. El dominico no había ocultado su interés por preparar una edición con sus homilías como reveló en diversas ocasiones, entre las que puede recordarse la carta que dirigió al infante don Martín desde Valencia el 20 de enero de 1386. El tenor de la carta invita a pensar que el infante había mostrado el deseo de disponer de alguna colección de sermones y que Vicente Ferrer se habría comprometido a prepararla ${ }^{1}$.

Este sermonario, según H. Fages,

no se compuso jamás, a pesar del buen deseo del autor, o se ha perdido hasta el punto de no quedar rastro alguno de él. No puede ser la recopilación que se conserva en el colegio del Patriarca de Valencia, ni la de Perusa, ambas bastante posteriores y poco dignas de ser ofrecidas a una persona real, a causa de las infinitas raspaduras que contienen ${ }^{2}$

Se desconocen, en la actualidad, los borradores originales, si existieron; se ignora, asimismo, si hubo o no fichas preparatorias previas a la exposición de los sermones. Ambos testimonios permitirían reconstruir el procedimiento de escritura de las homilías, escritas bien por Vicente Ferrer o bien por algún miembro de la compañía. El estado actual de los estudios no permite conocer la posible participación del dominico valenciano en la escritura material de sus propios sermones. No se conoce, tampoco, el paradero actual de sus autógrafos, de cuya existencia informó cabalmente Vicente Justiniano Antist ${ }^{3}$. No obstante, la existencia de tres manuscritos con schemata sermonum permite suponer que sí se procedió a reunir los esquemas en un único volumen; se trata de los manuscritos conservados en el convento de los dominicos de Perugia y en la Biblioteca Apostólica Vaticana respectivamente. Los dos manuscritos de la Biblioteca Apostólica Vaticana comienzan ambos el primer domingo de adviento con el tema: Ecce rex tuus [venit tibi] mansuetus, Mt 21, 5; por el contrario el número de temas recogidos en el manuscrito de Perugia es más extenso, en concreto transcribe 477 schemata, comenzando el domingo 22 después de la Trinidad.

Retrocedamos, no obstante, en el tiempo y trasladémonos a los años de vida de Vicente Ferrer y, más concretamente, durante el periodo en el que se dedicó a predicar por diversos países de Europa occidental, sin olvidar los inmediatamente posteriores y anteriores a la canonización. Ya se ha indicado que, en la actualidad, se desconocen, si los hubo, los posibles borradores

${ }^{1} C f$. Antist 1575, p. 111, reproducida en Garganta, Forcada 1956, p. 153.

${ }^{2}$ Cf. Fages 1903, pp. 59-60.

${ }^{3}$ Antist 1591,pp. 123-137, elaboró un elenco de todos los que tuvo noticia. 
originales de los sermones; tampoco se conocen los pro memoria que pudo utilizar el maestro Ferrer. Uno de los objetivos de este trabajo será el de intentar reconstruir el proceso seguido por los reportatores en la configuración del texto escrito de los sermones, cuyo contenido se conoce en la actualidad.

Resultaría de gran utilidad, a los efectos de reconstruir el proceso de elaboración del sermón, trazar el iter desde el momento en el que el predicador prepara en su estudio, en la celda, el guion de la homilía hasta el texto definitivo reelaborado por el reportador a partir de las notas tomadas en el momento de la exposición oral. La realidad que proporcionan los incunables se halla circunscrita a sermones íntegros, definitivos, cuya textualidad queda encerrada en las colecciones temáticas: de tempore, de sanctis y cuaresmales ${ }^{4}$. Los volúmenes manuscritos, por el contrario, exhiben un escenario mucho más rico y, por esta razón, más complejo para su sistematización. En realidad, las diferencias textuales de las colecciones manuscritas responden, unas, al estadio concreto y preciso de elaboración del texto, como por ejemplo las schedulae o schemata sermonum, es decir esquemas o fichas previas a la exposición oral pública; otras, por el contrario, a la temática en torno a la cual se organiza la colección o la serie, ya que puede tratarse de sermones correspondientes a un tiempo litúrgico, sermones predicados en un territorio determinado, entre otros.

Una primera aproximación a la tradición textual de los sermones predicados por Vicente Ferrer se puede leer en la voz Vincentius Ferrarii (Ferrerii) de Valentia, publicada en los Scriptores Ordinis Praedicatorum por Th. Kaeppeli y E. Panella ${ }^{5}$. Interesa, en esta ocasión, ofrecer una propuesta que permita reconstruir el itinerario seguido por los textos homiléticos transmitidos, entre la fase preparatoria, previa a la exposición oral y la elaboración de las notas tomadas por los reportatores y las copias manuscritas realizadas a partir de la edición definitiva preparada por el reportador. Así pues, la tradición textual de los sermones de Vicente Ferrer presenta un riquísimo panorama, del que en páginas sucesivas se proporcionará una primera aproximación.

Podrían distinguirse varios momentos en la transmisión: el primer paso lo representarían los manuscritos de esquemas, en el segundo se situarían los manuscritos de notas de los reportadores y los primeros borradores de las ediciones que ellos mismos preparaban con la intención de proporcionar a los futuros usuarios un texto elaborado ${ }^{6} \mathrm{y}$, finalmente, las copias acabadas por

\footnotetext{
${ }^{4}$ El lector interesado encontrará información en las bases de datos: ISTC (Incunabula Short Title Catalogue) (http://data.cerl.org/istc/_search), y en la GW (Gesamtkatalog der Wiegendrucke) (http://www.gesamtkatalogderwiegendrucke.de/) [consulta: 03/07/2018].

${ }^{5}$ Kaeppeli, Panella 1993, pp. 458-474.

${ }^{6}$ Perarnau 1999d.
} 
parte de los mismos reportadores. Estas versiones perfectas constituirían el punto de partida de la tradición textual posterior.

\subsection{Manuscritos de esquemas}

Por lo que respecta a los manuscritos de esquemas se han conservado tres códices que transmiten los esquemas previos a la exposición oral por parte del predicador. Se trata de los mss: Perugia en el convento de los dominicos ms. 477 [Schemata seu notulae sermonum de tempore simul et de sanctis in partibus Italiae septemtrionalis (Ianuae, Savonae) praedicatorum ( $\mathrm{m}$. nov. 1406-oct. 1407)] $]^{7}$; Biblioteca Apostólica Vaticana, ms. Vat Lat $4375^{8}$, y Biblioteca Apostólica Vaticana, ms. Vat Lat $7730^{9}$.

De los tres mencionados, el más extenso es el conservado en el convento de los dominicos de Perugia, y, quizá, es el más próximo al original, ya que presumiblemente el ms. que le sirvió de antígrafo fue el que escribió Vicente Ferrer atendiendo a la nota del comienzo:

Postquam per diversas nostri ordinis provincias 7 annis continuis discurrissem cotidie predicando et nichil inde scribendo, tandem in fine septimi anni, qui fuit 1407 annus gratie, incepi breviter scribere que sequuntur ${ }^{10}$

Esta nota se halla situada al comienzo del manuscrito y, según su contenido, el maestro Vicente Ferrer habría estado predicando durante siete años sin escribir nada y el año séptimo habría comenzado a escribir los schemata que reúne en el mencionado manuscrito. Ciertamente la anotación no es autógrafa de Vicente Ferrer, sino que se trataría de una copia elaborada a partir del antígrafo que bien podría haber sido escrito por el dominico valenciano; así lo sugieren los dos verbos empleados en primera persona. La identificación de la persona que predica y escribe, como prueba la utilización de los verbos discurrissem, pluscuamperfecto de subjuntivo, referido a la actividad pastoral llevada a cabo, y el pretérito perfecto de indicativo, incepi, relativo a la actividad de escritura del volumen invita a formular dicha hipótesis. Así pues, la primera persona permitiría suponer que fue Vicente Ferrer el autor intelectual y material de esta colección.

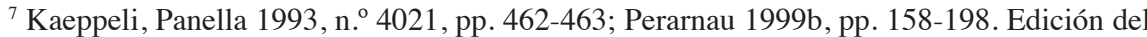
texto en Ferrer, Sermonario, ed. Gimeno, Mandingorra, 2006.

${ }^{8}$ Perarnau 1999b, pp. 198-228.

${ }^{9}$ Ibidem, pp. 228-256.

${ }^{10}$ Perugia. Convento dei Domenicani, ms. 477, f. 1v; $c f$. Ferrer, Sermonario, ed. Gimeno, Mandingorra, 2006, p. 43.
} 
De todos los esquemas reunidos tan solo uno de ellos corresponde con el pronunciado el día de Navidad, concretamente el n. ${ }^{\circ}$ 49: Sabbato. Die nativitatis Domini ${ }^{11}$. Durante los años en los que Vicente Ferrer se dedicó a la predicación, es decir entre 1399 y 1419, tan solo en tres ocasiones la festividad de la Natividad coincidió con un sábado, concretamente los años 1400 (Pascua 18 de abril), 1406 y 1417 (Pascua 11 de abril) ${ }^{12}$. Atendiendo a la referencia cronológica de la nota, comenzó a escribir el domingo vigésimo segundo después de la Trinidad del año 1406, es decir el 7 de noviembre. La coincidencia entre la información proporcionada por el manuscrito y el calendario de dicho año es completa, como se descubre al comparar ambas informaciones. Además, cuando comenzó a escribir habían transcurrido siete años predicando, ya que empezó a finales del año 1399, concretamente el 22 de noviembre ${ }^{13}$. Así lo había explicado él mismo en el sermón dedicado a santa Cecilia ${ }^{14}$. De este modo, entre el 22 de noviembre de 1399 y el 7 de noviembre de 1406 habían pasado siete años menos 15 días, los que median entre el 7 y la festividad de santa Cecilia.

Las notulae transcritas recogen la referencia a la festividad litúrgica en la que se predicó, el tema bíblico que empleó el predicador, la divisio thematis y la explanatio de todos los aspectos recogidos en la partición del tema. Mencionan con frecuencia las auctoritates que se pueden utilizar, si se estima oportuno, al objeto de organizar la exposición oral. Se incorporan, en ocasiones, sugerencias sobre el modo de estructurar la explicación por parte del orador. A modo de ejemplo ilustrarán los comentarios incorporados a la ficha correspondiente al sermón 469. De conversione beati Pauli ${ }^{15}$, en el que se sirvió del tema: Vas electionis mihi est iste, Act $9,15^{16}$. Allí se lee a continuación del mismo: Huius thematis introductio fiat iuxta auctoritatem illam, refiriéndose a la segunda epístola a Timoteo (2 Tim 2, 20-21). Acotado el pasaje bíblico referido, el esquema continúa informando al usuario sobre el modo de proceder en la peroración y explica: Prosequtio autem fiat dupliciter. Primo, sumendo tema in persona Christi, mencionando el tema. Seguidamente aconseja narrar la historia de la conversión de Pablo: Et hic narretur ad litteram tota historia sue conversionis prout in epistola continetur, finalizando con un pasaje del Eclesiastico 43, 2, 9. En segundo lugar, sugiere que puede utilizarse

${ }^{11}$ Ibidem f. 12r, cf. Ferrer, Sermonario, ed. Gimeno, Mandingorra, 2006, n. ${ }^{\circ} 49$, pp. 111-112.

${ }^{12}$ Se utiliza el calendario correspondiente a dichos años publicado en Cappelli 1978, pp. 9091, año 1400; pp. 76-77, años 1406 y 1417.

${ }^{13}$ Garganta, Forcada 1956, p. 37.

${ }^{14}$ Citado por Chabás 1995, p. 293; cf. Martínez Ferrando 1952, p. 16.

${ }^{15}$ Perugia. Convento dei Domenicani, ms. 477, f. 97r; $c f$. Ferrer, Sermonario, ed. Gimeno, Mandingorra, 2006, p. 609.

${ }^{16}$ Ibidem; Perarnau 1999e, n. ${ }^{\text {8 } 863, ~ p . ~} 788$. 
el ejemplo de cualquier pecador: $2^{\circ}$, sumendo tema in persona cuiuscumque peccatoris.

\subsection{Libri reportationum}

Algunos manuscritos califican la colección de textos que transmiten con el sustantivo reportationes, como por ejemplo el ms. 279 del Archivo de la Catedral de Valencia el cual alude a sí mismo como reportaciones sermonum reverendisimi magistri Vincencii Ferrarii predicatoris finis mundi ${ }^{17}$. Además, conviene recordar el manuscrito de Friburgo con la cuaresma de 1404 reportada por Friedrich von Amberg; allí el reportador se refiere a su actividad de toma de notas con el verbo reportar, reportavi meliori modo quo potui ${ }^{18}$. Del mismo modo, el manuscrito 610 de la Biblioteca Municipal de Aviñón recuerda que existían colecciones de reportaciones como descubre el índice del final del manuscrito; allí se pueden leer las siguientes anotaciones:

(1) "IDominica 3a. 'Humiliamini sub potente manu Dei ut vos exaltet', require in libro qui incipit: 'Ecce rex tuus', ubi sunt reportationes magistri Vincencii"; (2) "IDominica 4a. "Estote misericordes [sicut] pater vester misericors est', etc. Require alia themata et sermones in libro qui incipit: 'Ecce rex tuus', ubi sunt reportationes magistri Vincencii”, y (3) "IDominica 5a' .Exi a me Domine quia homo', fol. 30a. Require $5^{\mathrm{e}}$ sermones in libro qui incipit : 'Ecce rex tuus', etc, ubi sunt reportationes magistri Vincentii" ${ }^{19}$.

Quizá se trata, en todas las ocasiones, del mismo manuscrito, porque el autor del índice registra las palabras con las que comienza el mencionado códice y menciona el tema predicado el primer domingo de adviento: Ecce rex tuus venit tibi mansuetus, Mt 21, 5. Curiosamente los dos manuscritos de esquemas de la Biblioteca Apostólica Vaticana principian con la misma cita bíblica $^{20}$. Cabe pensar que se trataba de los libros de las notas del reportador tomadas en el momento de la homilía, o, tal vez presentaban ya una edición

\footnotetext{
${ }^{17}$ Valencia. Archivo Catedral, ms. 279, f. 1r ; cf. una descripción en Olmos 1943, p. 202, n. ${ }^{\circ} 279$.

${ }^{18}$ Friburgo (Suiza). Couvent des Cordeliers, ms. 62, f. 45r, $c f$. Bénédictins du Bouveret 1965-1982, II, n. ${ }^{\circ}$ 4455, p. 115; Ferrer, Sermones, ed. Gimeno, Mandingorra, 2009, p. 47; Perarnau 1999a, p. 70.

${ }^{19}$ Aviñón. Bibliothèque municipale, ms. 610, f. 279r; $c f$. Ferrer, Sermonario de Aviñón, ed. Gimeno, Mandingorra, en prensa.

${ }^{20}$ Biblioteca Apostólica Vaticana, ms. Vat. Lat. 4375, f. 1r; ms. Vat. Lat. 7730, f. 7r; cf. Perarnau 1999b, p. 200 y 229.
} 
manuscrita en la que se distinguía entre los sermones de tempore y los de sanctis a juzgar por el hecho de que el autor del índice invita, concretamente el día de Pascua, al lector a consultar otro volumen y dice de él: require in libro de sanctis folio $158 b^{21}$.

Una pintura de principios del siglo XVI descubre y perpetúa la importantísima actividad de los reportadores en la transmisión de los sermones de Vicente Ferrer. El procedimiento de escritura se iniciaría en el instante mismo de la homilía para los sermones in extenso, no así para las colecciones de schemata. Por lo que respecta a los sermones in extenso, el punto de partida puede situarse en el retablo de san Vicente Ferrer pintado por Miguel de Prado (documentado entre 1515 y 1537) procedente del convento de san Onofre de Museros, que ingresó en el Museo de Bellas Artes a resultas de la desamortización de Mendizábal. Allí aparece el maestro Vicente Ferrer predicando al auditorio congregado. A sus pies, los reportadores, tal vez miembros de la compañía, como Antonius Anglade o frater Moya, atentos a la peroración toman notas en sendas hojas desplegadas entre sus piernas ${ }^{22}$. Su presencia no pasó desapercibida a la concurrencia, a la par que debía de ser frecuente, como recordaron muchos de los testimonios que declararon en el proceso de canonización, como se verá más adelante. El reportador es, en consecuencia, un intermediario entre la palabra pronunciada en el contexto de la oralidad y la transcripción escrita que él mismo transforma en un discurso escrito. Lo recordaba Ovidio en la Metamorfosis: Ingeminat voces: auditaque verba reportat (III, 369).

No produce extrañeza, en consecuencia, que el verbo reportare, durante la Edad Media, fuese sinónimo de transcribere y que el sustantivo reportatio lo sea de commentationes, adnotationes ${ }^{23}$. Del mismo modo, el Diccionari català-valencià-balear, en la segunda acepción, lo define como portar una noticia; referir, contar, exposar verbalment o per escrit, aduciendo como prueba algunos testimonios documentales tales como: Notari públich ... qui aquestes coses ha escrit e clos en pública forma reportat, según un documento del año 1293; En un libre són reportades les solemnitats, según otro datado en 1392 o, incluso en el capítulo 60 del Tirant se lee: Per ço que si los metges venguessen no u reportasen a l'emperador ${ }^{24}$. Jacqueline Hamesse definía la reportación como une copie faite par un auditeur lors d'un sermon ou d'un cours $^{25}$.

${ }^{21}$ Aviñón. Bibliothèque municipale, ms. 610, f. 280r; $c f$. Ferrer, Sermonario de Aviñón, ed. Gimeno, Mandingorra, en prensa.

${ }^{22}$ Martínez Ferrando 1952, p. 7; Riquer, Comas, Molas 1984, p. 399.

${ }^{23}$ Du Cange 1954, vol. VII, p. 132.

${ }^{24}$ Alcover 1980, vol. IX, p. 384.

${ }^{25}$ Hamesse 1988, p. 83, véase también Colli 1990, p. 234. 


\subsection{Manuscrito de reportador}

Una vez tomadas las notas por parte del reportador comenzaría el proceso de reelaboración posterior. Trabajaría asistido por las notas que él mismo había tomado, como recuerda el índice del manuscrito 610 de la Biblioteca Municipal de Aviñón. De esta fase de escritura conservamos un testimonio de excepción representado por el sermonario custodiado en el Real Colegio y Seminario del Corpus Christi de Valencia ${ }^{26}$; se trata en esta ocasión del manuscrito de un reportans que permite reconstruir las sucesivas etapas de escritura del sermón teniendo en cuenta que el texto es el fruto de una acción continuada en el tiempo.

Reconstruyamos el proceso seguido por los miembros de la compañía atendiendo a la materialidad del mismo. El reportador comenzaría la elaboración del manuscrito colocando en el centro de la página el título del sermón, es decir el lugar en el que se pronunció, el día y la festividad ${ }^{27}$, escrito todo ello entre llaves. Inmediatamente registró en el margen izquierdo la palabra Tema, a continuación de la cual anotó el pasaje bíblico que servía a tal efecto. La puesta en página utilizada recuerda la de los manuales notariales, especialmente los protocolos contemporáneos, tanto por sus dimensiones como por la forma de ocupación del espacio gráfico. El reportador distribuye en la página en blanco el esqueleto del futuro sermón; el esquema lo vertebran las auctoritates, anotando la referencia correspondiente al libro bíblico y al capítulo respectivo en el margen izquierdo; en el centro de la página el texto íntegro de la cita bíblica. Entre una cita y otra queda un espacio en blanco como ponen al descubierto algunos de los folios del manuscrito, por ejemplo los folios LXVIII44v, LXVIIII45r, LXXI47r, XCIII70r-v, CVII82v, CLVI129r, CLIXI133v, CLXI134r-CLXIIIII138r, CLXVIIII142r, entre otros. Los espacios blancos servirán para incorporar con posterioridad los comentarios que sugieren los pasajes bíblicos que se utilizan para estructurar el sermón. De igual modo sucede con la divisio thematis, elemento clave en la configuración definitiva de la homilía. Los espacios blancos y los añadidos textuales que en ellos se alojaron descubren la continuación en el tiempo del proceso creativo. La evidencia material de este modo de proceder la desvelan las incorporaciones interlineares sustituyendo secuencias textuales canceladas previamente ${ }^{28}$; las

\footnotetext{
${ }^{26}$ Quetif 1719, I, p. 767, reconstruye parcialmente la historia de este manuscrito; véase, además, los estudios de Brettle 1924, pp. 95-104; Cátedra 1983-1984, pp. 280-286; Perarnau 1999c; Robres 1955.

27 Valencia. Real Colegio y Seminario del Corpus Christi, sermonario de san Vicente (= Corpus Christi), f. 7v, cf. Ferrer, Sermonario de San Vicente Ferrer, ed. Gimeno, Mandingorra, 2002, facsímil.

${ }^{28}$ Como en f. LXIXI46v.
} 
adiciones marginales ${ }^{29}$; los añadidos incorporados en tiempos diferentes como evidencia la diversa tonalidad de las tintas empleadas ${ }^{30}$. Las más llamativas resultan ser aquellas adiciones que superan el espacio a ellas destinado y se desplazan por las zonas blancas supérstites que en principio no tenían reservadas $^{31}$. En ocasiones, las nuevas incorporaciones textuales, atendiendo a su extensión, se escribieron con grafías de módulo menor a las del resto, al objeto de poder registrar todo el texto que se debía incorporar. La utilización de letras de módulo menor, especialmente en las adiciones, acomodándose al espacio blanco del que disponen, se localizan con mayor intensidad y frecuencia a partir del f. CLXXXI154r y desde aquí hasta el final. El resultado de este modo de proceder encuentra paralelismos con el manuscrito de autor, caracterizado por la acumulación de múltiples enmiendas y correcciones ${ }^{32}$. Hace años defendí que este manuscrito se trataba de un autógrafo de Vicente Ferrer, hipótesis que fue criticada por Perarnau, aduciendo elementos que ponen de relieve la intervención de varias personas en la escrituración del manuscrito ${ }^{33}$. Se trata de una copia inconclusa, como ponen de relieve las sucesivas intervenciones gráficas a las que se ha aludido. Se desconoce, no obstante, el número y nombre de todos los que escribieron en el mismo. Este manuscrito precisa de un análisis paleográfico que individualice las diferentes personas-manos que intervinieron en su elaboración, estudio gráfico que acometeré en el futuro.

El sermonario del Patriarca ha conservado un conjunto de noticias explicativas de la relación existente entre la predicación y los predicadores, por una parte, y los responsables de la escritura del manuscrito, por otra. Veamos algunos de los testimonios conservados. El primero se localiza en el sermón: Quomodo posumus viam scire ${ }^{34}$, Io 14, 5, predicado In eadem feria VI et festo apostolorum Filipi et Jacobi ${ }^{35}$, el viernes primero de mayo. Al concluir su homilía Vicente Ferrer anunció la predicación que llevaría a cabo un fraile de su compañía por la tarde. Decía el dominico valenciano:

Et ita habetis sermonem expletum de beato Filipo. Sed si volueritis audire sermonem de beato Jacobo, unus ex meis sociis post prandium, ora none, predicabit vobis, etc. Et cras, que est dies

\footnotetext{
${ }^{29}$ Como en ff. LIIII32v, LIIIII33v, 121v, 146v.

${ }^{30}$ Como en ff. 99r, 103r-v, 104r, 111v-112v, 114r-118v, 121r, entre otros.

${ }^{31}$ Véase a modo de ejemplo el f. $3 r$.

${ }^{32}$ Sobre el manuscrito de autor se encontrará información útil en los trabajos de Petrucci 1985a, 1985b, 1985c, 1985d y 1992-1993; véase también, especialmente sobre las variantes de autor, la obra clásica de Pasquali 1988, cap. 7 (“Edizioni originali e varianti d'autore").

${ }_{33}^{33}$ Perarnau 1999c, p. 402.

${ }^{34}$ Perarnau 1999e, n. ${ }^{\circ} 723$, pp. 742-743.

${ }^{35}$ Corpus Christi, ff. LXII38v-LXIII/40r.
} 
sabati, reddemus ad materiam relictam de antichristo, scilicet de tempore quando veniet ${ }^{36}$.

El tema elegido por el socius fue Solvi te ${ }^{37}$, Mt 21, 2, materia que explicó del siguiente modo: "Bona gent, verba ista sunt scripta per sanctum Mateum a XXI capitulo, sentencia est ista: Desatete vel desligado t'e, et potest intelligi tribus modis, e inmediatamente prosigue con la divisio thematis que expone del siguiente modo: Primo, de Christi condicione miraculosa; $I I^{o}$ de peccatoris conversione graciosa; $I I^{o}$, de sacerdotum iurisdictione virtuosa. El final del comentario del tercer apartado coincide con el final del f. LXIII/40r. El reportador anotó en el margen superior del f. LXIIIl40v la siguiente nota relativa a la prosecución del sermón que estaba copiando:

Et quia reverendus magister hodie predicavit vobis de beato Filipo, dicam vobis de beato Iacobo, recitando eius ystoriam, que narrat quatuor in quibus fuit singulariter virtuosus, ut sequitur

y a continuación, de nuevo, prosigue con una nueva divisio thematis en la que aborda cuatro aspectos diferentes relativos a la vida de Santiago. Concluye el sermón con la nota alusiva al fraile que realizó aquella prédica vespertina. Dice así: Istum sermonem fecit frater Johannes de Alcoy ${ }^{38}$.

Llama la atención la utilización del verbo en primera persona por parte del socius que predicó sobre la vida de Santiago el menor, cuando para completar la predicación del maestro, se propone él, dicam vobis, abordar la vida del segundo santo del día a partir de algún relato hagiográfico. La mano que escribe esta advertencia y la identificación del fraile que predicó es la misma, razón por la cual Perarnau i Espelt sugería que Juan de Alcoy és un bon aspirant al títol de copista del manuscrit conservat al Col-legi del Patriarca de València, si no del seu antígraf ${ }^{39}$. Maravilla que el fraile que predicó aquella tarde reclame la autoría del sermón, más verosímil parece que esta reivindicación la anotase en el antígrafo y a partir de él se incorporase la autoría a la copia del Patriarca, donde se unificaría la escritura de ambas, la del sermón y la de la nota. La intervención gráfica de Juan Alcoy, en esta ocasión, exigiría practicar las comparaciones paleográficas oportunas. Para ello se precisaría disponer de un autógrafo indubitable de la persona que escribió esta nota y, por tanto, todo el sermón.

\footnotetext{
${ }^{36}$ Ibidem, f. LXIII|40r; Ferrer, Sermonario de San Vicente Ferrer, ed. Gimeno, Mandingorra, 2002, pp. 218-219; Cátedra 1994, p. 47; Perarnau 1999e, p. 404.

${ }^{37}$ Perarnau 1999e, n. ${ }^{\circ} 809$, p. 768.

${ }^{38}$ Corpus Christi, f. LXIIII40v; Ferrer, Sermonario de San Vicente Ferrer, ed. Gimeno, Mandingorra, 2002, pp. 221; Cátedra 1994, p. 47-48; Perarnau 1999e, p. 404.

${ }^{39}$ Cf. Perarnau 1999c, p. 404.
} 
El domingo 3 de mayo (In eadem villa, die dominica III ${ }^{a}$ post Pasca et festum Sancte Crucis $^{40}$ ) predicó a partir del tema: Mihi absit gloriari, nisi in cruce, Gal 6,1441. Allí indica Vicente Ferrer que ese día la iglesia celebraba dos festividades en los siguientes términos:

Due magne solepnitates et festa sunt hodie, scilicet primo Sancte Crucis, et de ista facit sancta mater Ecclesia hodie totum officium, et similiter erit noster sermo; alia solempnitas est de die dominico, qui est magnum festum, et Ecclesia solempniçat eum propter resurreccionem Christi qui resurrexit tali die sicut dominica. Et de ista solepnitate predicabit post prandium unus ex sociis meis, scilicet frater Moya ${ }^{42}$.

Vicente Ferrer predicó la mañana del domingo 3 de mayo y su socius lo hizo por la tarde como el mismo anunció al principio del sermón Modicum, scilicet, penitencie recipite, et videbitis me, Io 16, 1943; allí el socius anotó: Et quia magister dixit hodie quod post prandium predicaretur de dominica vobis, ideo ista predicacio erit de sancto Evangelio hodierno ${ }^{44}$.

El reportador/copista que elaboraba paulatinamente el manuscrito de sermones tuvo problemas de salud a lo largo del año 1411. Así el 16 de mayo, en el que debía de copiar el sermón correspondiente a la Dominica IIII ${ }^{a}$ proxima ante Ascensionem ${ }^{45}$, en Alcaraz (Albacete), el reportador anotó: Et hic fui infirmus ab hac die usque ad Pentecostem exclusive. Como consecuencia de esta enfermedad faltan unos cuantos sermones, según él mismo anunció: Et ideo deficiunt plures sermones hic usque ad illam diem. La enfermedad duró, a juzgar por los sermones transcritos, hasta el domingo de Pentecostes, que el año 1411 fue el 31 de mayo. A partir de este día comienza de nuevo a transcribir los sermones predicados por Vicente Ferrer, empezando por el que pronunció el día de Pentecostes: In die Pentecostes, in loco de la Moraleia ${ }^{46}$,

${ }^{40}$ Corpus Christi, f. LXIVI41v; Ferrer, Sermonario de San Vicente Ferrer, ed. Gimeno, Mandingorra, 2002, pp. 226; Cátedra 1994, p. 48; Perarnau 1999e, n. ${ }^{\circ}$ 517, p. 663.

${ }^{41} C f$. Perarnau 1999e, n. ${ }^{\circ}$ 517, pp. 663-664.

${ }^{42}$ Corpus Christi, f. LXIVI41v; Ferrer, Sermonario de San Vicente Ferrer, ed. Gimeno, Mandingorra, 2002, pp. 226.

${ }^{43}$ Corpus Christi, f. LXVI|43r; Ferrer, Sermonario de San Vicente Ferrer, ed. Gimeno, Mandingorra, 2002, p. 233; Cátedra 1994, p. 48; cf. Perarnau 1999e, n. ${ }^{\circ}$ 53, p. 423.

${ }^{44}$ Ibidem, f. LXVI|43r; Ferrer, Sermonario de San Vicente Ferrer, ed. Gimeno, Mandingorra, 2002, p. 233

${ }^{45}$ Ibidem, f. LXXVIIIII57v; Ferrer, Sermonario de San Vicente Ferrer, ed. Gimeno, Mandingorra, 2002, p. 294; Cátedra 1994, p. 51.

${ }^{46}$ Ibidem, f. LXXIXI57v; Ferrer, Sermonario de San Vicente Ferrer, ed. Gimeno, Mandingorra, 2002, p. 295; Cátedra 1994, p. 51. 
utilizando el tema: Repleti sunt omnes Spiritu Sancto, Act 2, $4^{47}$. No había transcurrido todavía un mes, cuando el 14 de junio, de nuevo, el reportador informa al lector que se halla indispuesto y por esta razón no pudo incorporar todos los sermones que pronunció el maestro Ferrer; así al final del sermón correspondiente al primero de junio (In eodem loco, feria $I^{\alpha 48}$ ), anotó: Hic deficiunt plures sermones propter infirmitatem meam duplicatam que iterum venit mihi, etc ${ }^{49}$.

El manuscrito, coincidiendo con el 13 de agosto, transcribe el sermón pronunciado en Illescas (Toledo) (In villa de Yllescas, feria $V^{a}$ ), en el que utilizó el tema: Sancti per fidem vicerunt regna, Hebr 11, 33 ${ }^{50}$. En esta ocasión el reportador registró diversas anotaciones relativas a la autoría. Inmediatamente después del título incorporó: Et IIII ${ }^{a}$ feria vacat propter infirmitatem magistri; a continuación, después del inicio de la prédica reconoce que los allí congregados habían acudido no para oírle a él sino a Vicente Ferrer ${ }^{51}$. El reportador, del mismo modo que actuó con el sermón pronunciado por fray Juan de Alcoy, anotó también aquí quien fue el encargado de pronunciarlo: Hunc sermonem fecit prior ordinis predicatorum de Toledo.

El reportador enfermó, de nuevo, con posterioridad al 13 de agosto, según recuerda una nota incorporada en el folio CXX196v a continuación del final del sermón de Illescas, que predicó el prior de Toledo. Allí se lee:

$\mathrm{Ab}$ ach (sic) die usque ad adventum, qui incipit hodie, fui impeditus propter infirmitatem, que duravit mihi sex septimanas, et debilitatio usque ad hodiernum diem. Et ideo, sentiens me jam in convalecencia incepi hodie scribere sermones, sicut consuevi ${ }^{52}$.

El siguiente sermón presenta como título: Dominica prima adventus y el tema utilizado fue: Benedictus qui venit in nomine Domini, Mt 21, $9^{53}$. La enfermedad del reportador se prolongó durante seis semanas, a tenor de la nota, sin embargo faltan muchos más sermones, pues el copista no vuelve a

\footnotetext{
${ }^{47}$ Ibidem, f. LXXIXI57v; Ferrer, Sermonario de San Vicente Ferrer, ed. Gimeno, Mandingorra, 2002, p. 295; Cátedra 1994, p. 51; Perarnaru 1999e, n. ${ }^{\circ}$ 747, p. 751.

${ }^{48}$ Ibidem, f. LXXXI58v; Ferrer, Sermonario de San Vicente Ferrer, ed. Gimeno, Mandingorra, 2002, p. 299; Cátedra 1994, p. 52.

${ }^{49}$ Ibidem, f. LXXXIII60r; Ferrer, Sermonario de San Vicente Ferrer, ed. Gimeno, Mandingorra, 2002, p. 299; Cátedra 1994, p. 52.

${ }^{50}$ Ibidem, f. CXX196r; Ferrer, Sermonario de San Vicente Ferrer, ed. Gimeno, Mandingorra, 2002, p. 470; Cátedra 1994, p. 62; Perarnau 1999e, n. ${ }^{\circ} 758$, p. 754.

${ }^{51}$ Ibidem, f. CXX196v.

${ }^{52}$ Ibidem, f. CXX196v; Ferrer, Sermonario de San Vicente Ferrer, ed. Gimeno, Mandingorra, 2002, p. 471; Cátedra 1994, p. 63 n. ${ }^{\circ}$ 126; Perarnau 1999c, p. 403.

${ }^{53}$ Cf. Perarnau 1999e, n. ${ }^{\circ} 79$, pp. 508-509.
} 
transcribir sermones hasta el primer domingo de adviento, es decir hasta el 29 de noviembre, de $1411^{54}$. Así pues, el relato de los sermones se interrumpe entre el 14 de agosto y el 28 de noviembre. El copista indica que estuvo enfermo seis semanas: ¿qué ha sucedido con los sermones que faltan? El vacío textual se prolonga a lo largo de las 14 semanas siguientes. Pedro Cátedra ha formulado la siguiente hipótesis explicativa:

Pudiérase pensar que el reportador se refiere al tiempo que estuvo predicando san Vicente durante el cual estuvo enfermo, pues es posible que el santo estuviera enfermo desde el día 1 de agosto hasta mediados de octubre, y coincidiera el reinicio de su actividad con el de la enfermedad del reportador de su compañía ${ }^{55}$.

\section{4. ... in sexternis sequentibus propia manu conscripsi}

De todos los manuscritos conservados, la cuaresma de 1404 predicada en Friburgo (Suiza) aporta una información de capital trascendencia sobre el proceso de escritura de los sermones a partir de las notas tomadas en el momento de la predicación. El reportador, además de identificarse, anotó en el manuscrito:

Notandum est quod anno Domini $\mathrm{M}^{\circ} \mathrm{CCCC}_{\text {IIII }}^{\circ}$ quidam famosus predicator de ordine Iacobitarum, nomine magister Vincencius Ferrarii, de Valencia magna oriundus, ad Friburgum Ochtlandie applicuit et in medio Quadragesime ibidem predicare cepit per totam illam septimanam, postea vero se transtulit ad villas circumiacentes. Quem ego, frater Fridericus, minister fratrum minorum provincie superioris Alemanie, sacre theologie professor, associans et sequens usque ad dominicam Palmarum, reportavi omnes sermones quos tunc predicavit de ore suo, meliori modo quo potui, et in sexternis sequentibus propria manu conscripsi, etc ${ }^{56}$.

El autor de la reportación, Friedrich von Amberg, ofm, (1384?$\uparrow 1432)^{57}$, se incorporó al sequito que acompañaba a Vicente Ferrer, como él

${ }^{54}$ Cf. Cappelli 1978, pp. 78-79.

${ }_{55}^{55}$ Cf. Cátedra 1994, p. 63.

${ }^{56}$ Friburgo (Suiza). Couvent des Cordeliers, ms. 62, f. 45r, $c f$. Bénédictins du Bouveret 1965-1982, II, n. ${ }^{\circ} 4455$, p. 115; Ferrer, Sermones, ed. Gimeno, Mandingorra, 2009, p. 47; Perarnau 1999a, p. 70; Scarpatetti 1983, I, n. ${ }^{\circ} 387$, p. 140; II, ilustración 185; reproducción del sermón In Friburgo feria quinta post Letare. De extremo iudicio (f. 61r), cf. Steffens 1910, facsímil 110 .

${ }^{57}$ Sobre la biografía de este monje véase: Hodel 1993, pp. 149-154; Jörg 1975, pp. 82-83; Utz Tremp 1995, pp. 81-109. 
mismo lo indica, associans et sequens, y les acompañó desde el día 9 hasta el 21 de marzo de 1404. Durante esos días tomó notas de cuantos sermones predicó el dominico valenciano: reportavi omnes sermones quos tunc predicavit de ore suo. Tomar nota de alguien que habla exige celeridad en la mano que escribe, y no siempre el que toma notas queda satisfecho con su trabajo, esta es la razón por la cual Friedrich von Amberg expia sus errores mediante la expresión meliori modo quo potui. Con toda seguridad, el franciscano los días posteriores se dedicó a dar forma a aquellas notas preparando un texto legible, tal y como lo encontramos en la actualidad en el manuscrito 62 del convento de los Cordeliers de Friburgo. El manuscrito, al menos en esta parte, muestra una copia manuscrita en limpio de los 16 sermones predicados en tierras helvéticas. Friedrich vom Amberg reelaboró, a posteriori, el texto a partir de las notas y él mismo preparó la copia que se lee en la actualidad, lo que proclamó como conclusión de esta nota preliminar: et in sexternis sequentibus propia manu conscripsi.

\subsection{Antonio Anglada y el manuscrito de Aviñón}

El 17 de diciembre de 1403, Vicente Ferrer, desde Ginebra, dirigió una extensa carta a Jean de Reynoix, general de los dominicos ${ }^{58}$. En ella el dominico valenciano informa al General de cuáles son sus intenciones para el futuro inmediato, entre las que refiere su deseo de predicar en Friburgo durante la cuaresma ya que ha sido invitado a ello por el obispo de Lausana, Guillermo III de Menthonay (1394, agosto $22-\uparrow 1406$, julio 8$)^{59}$. En ella alude a la compañía de un socius, socius meus frater Antonius, que tal vez era uno de sus estrechos colaboradores, uno de los que podía ayudarle a preparar una edición manuscrita de los sermones. Invita a pensar en esta colaboración la coincidencia del apelativo Antonius, con el nombre de pila de otro reportador conocido, al que se debe la reportatio de los sermones pronunciados por Vicente Ferrer en Mallorca, entre septiembre de 1413 y el mes de enero de $1414^{60}$.

El manuscrito 610 de la Bibliothèque Municipale de Aviñón ${ }^{61}$ ha conservado la memoria, el testimonio de este dominico que acompañó a

\footnotetext{
${ }^{58} C f$. Hodel 2006, pp. 189-203, la edición de la carta en pp. 200-203, incluye también una reproducción de la carta original, conservada en el convento de San Rocco di Acireale.

${ }^{99}$ Cf. Ferrer, Sermones, ed. Gimeno, Mandingorra, 2009, p. 13; Gams 1957, p. 284; Eubel 1913, p. 297.

${ }^{60}$ Sobre la predicación mallorquina, véase Esponera 2005b; Pérez Martínez 1957-1958; Roselló 1987. La estancia de san Vicente en la isla se ha conservado en el imaginario como se puede valorar en Valriu, Vibot 2010.

${ }^{61}$ Cf. Catalogue Général 1894, pp. 343-345; Ferrer, Sermonario de Aviñón, ed. Gimeno, Mandingorra, en prensa; Perarnau 1974; Sanchis Sivera 1999.
} 
Vicente Ferrer a lo largo de su periplo mallorquín, y aún por otros lugares, como descubren algunas notas presentes en el mencionado manuscrito. Veámoslas. En diversas ocasiones registró una especie de exlibris, expresado mediante el siguiente texto: Iste liber est fratris Anthonii Anglade, ordinis predicatorum conventus Avinionis ${ }^{62}$. La mencionada anotación la volvió a incluir de nuevo en los folios $130 \mathrm{r}$ y en el $277 \mathrm{v}$, según la numeración moderna ${ }^{63}$. No es este el único manuscrito de la Biblioteca Municipal de Aviñón que conserva el exlibris de Antonio Anglada: sirvan a modo de ejemplo los manuscritos $66,84,85$ y $1032^{64}$. Los catalogadores de los manuscritos de la mencionada biblioteca afirmaron de Antonio Anglada que este dominico fue copiste d'un certain nombre de manuscrits, et qui s'etait mis pendant quelques temps a la suite de S. Ferrier ${ }^{65}$. Así parece desprenderse de dos noticias presentes en el manuscrito aviñonés. En efecto, en el interior de la cubierta anterior se lee: Ihesus. Littera f. Anno Domini $M^{o} C C C C^{o} X V^{o}$ et die $\left[V I I^{a}\right.$ junii e]go frater Anthonius Anglade eram in Valencia et fuit eg[li]ptis inter V et VI horam post ortum solis ${ }^{66}$. Es decir Antonio Anglada estuvo presente en Valencia los primeros días de junio de 1415. El itinerario de Vicente Ferrer, sin embargo, no registra su presencia dicho mes en la ciudad del Turia ${ }^{67}$. El folio $25 \mathrm{r}$ del manuscrito aviñonés conserva un apunte escrito por el mismo Anglada que pone al descubierto la actividad llevada a cabo por este dominico mientras acompañaba a Vicente Ferrer; concretamente da la impresión que era el reportador de sus prédicas, como se desprende de la anotación:

Anno Domini $\mathrm{M}^{\circ} \mathrm{CCCC}^{\circ} 15$ et die prima julii recessit magister Vincentius de Ceragosta et ivit Perpinianum ad unionem Ecclesie, et tunc dedit mihi bonam solidatam pro labore meo, littera f, illo anno ${ }^{68}$.

No hay lugar a dudas. La nota alude al viaje iniciado por el maestro Ferrer desde Zaragoza en dirección a Perpiñán para tratar de la unión de la iglesia y solucionar, así, el problema del Cisma de Occidente; a Perpiñán llegó a finales del mes de agosto, donde permaneció hasta después de la Epifanía

\footnotetext{
${ }^{62}$ Aviñón. Bibliothèque Municipale, ms. 610, f. 1r, $c f$. Ferrer, Sermonario de Aviñón, ed. Gimeno, Mandingorra, en prensa, estudio introductorio.

${ }^{63}$ Ibidem, ff. 130r, 277v, cf. Ferrer, Sermonario de Aviñón, ed. Gimeno, Mandingorra, en prensa, estudio introductorio.

${ }^{64}$ Cf. Catalogue Général 1894,pp. 39, 47-49 y 483.

${ }^{65}$ Ibidem, p. 483.

${ }^{66}$ Aviñón. Bibliothèque Municipale, ms. 610, interior cubierta delantera; $c f$. Ferrer, Sermonario de Aviñón, ed. Gimeno, Mandingorra, en prensa, estudio introductorio.

${ }^{67}$ Cf. Riera 2013, pp. 426, 440-441.

${ }^{68}$ Aviñón. Bibliothèque Municipale, ms. 610, f. 25r, $c f$. estudio introductorio y edición del texto, en Ferrer, Sermonario de Aviñón, ed. Gimeno, Mandingorra, en prensa.
} 
del año $1416^{69}$, una vez publicada la sustracción de la obediencia a Benedicto $\mathrm{XIII}^{70}$. Además, alude a su actividad como reportador y a la percepción de una soldada como compensación económica por su actividad como copista (bonam solidatam), la cual le entregó el mismo Vicente Ferrer a juzgar por el tenor de los tiempos verbales en tercera persona del singular del pretérito perfecto de indicativo: ivit y dedit, es decir coinciden la persona que emprendió el viaje y además le pagó. No debe maravillarnos que en ese momento, durante la primera mitad del año 1415, se encontrase reelaborando las notas que había tomado a lo largo del periplo mallorquín, incluido en el manuscrito aviñonés, en el que, además, se recogen sermones anteriores.

El manuscrito de Aviñón, finalmente, presenta al lector una copia perfectamente elaborada, han desaparecido los testimonios gráficos derivados del proceso creativo (enmiendas, correcciones, cancelaciones, adiciones interlineares, etc.) y han sido sustituidos por una escritura uniforme. El copista, Antonio Anglade, advierte, además, a los futuros usuarios que los textos de los sermones recogidos han sido sometidos a una corrección, cotejando la copia con el antígrafo, tanto en lo que se refiere al texto como al lenguaje y léxico empleados, atendiendo a la presencia de la abreviatura "cor" (correctus) $)^{71}$ colocada al comienzo de cada sermón a la altura de la capitular en el margen izquierdo. Informa, del mismo modo, a los futuros usuarios, entre los que se encontrarían también los copistas, de las ausencias de texto, especialmente han quedado espacios en blanco en algunas ocasiones en las que se debía de incluir tras el libro bíblico el número de capítulo; en estos casos ha escrito en el margen la abreviatura "co", que tal vez deba desarrollarse por comple, imperativo del verbo complere, o, incluso, por el infinitivo mismo.

\section{2. ¿QUIÉNES ESCRIBÍAN?}

¿Quiénes escriben? ¿Quiénes son los reportadores? El proceso de canonización $^{72}$ proporciona alguna información al respecto, es decir sobre el trabajo

${ }^{69} C f$. Riera 2013, pp. 426-427. Sobre las reuniones que tuvieron lugar en Perpiñán, cf. Zurita 2007, libro XII, capítulos LI (pp. 438-440), LIII (pp. 444-446) y LVII (pp. 459460); Antist 1575, I, capítulo XXVI; Teixidor 1999, I, capítulos XXXVIII (pp. 439-443), XXXIX (pp. 445-450), XL (pp. 451-458); Fages 1903, II, pp. 91-100; Garganta, Forcada 1956, pp. 73-74.

${ }^{70} C f$. Martínez Ferrando 1955, docs. 61, 62, 63 y 64, pp. 99-103.

${ }^{71}$ Costumbre extendida en ámbito universitario, en el que se indicaba al concluir el cuaderno que este había sido revisado, $c f$. Destrez 1935, p. 52.

${ }^{72}$ Valencia. Universitat de València. Biblioteca Histórica, ms. 690; cf. Gutiérrez 1913, vol. III, n. ${ }^{\circ} 1869$, p. 62. 
llevado a cabo por los reportatore ${ }^{73}$ para registrar y fijar las palabras del dominico. Entre los testigos que valoraron el proceso de escritura de las homilías se encuentran los siguientes: (1) Bernardo de Rosier, arzobispo de Toulouse ${ }^{74}$ comentó:

plures valentes viri, theologi et juriste, tam in jure canonico quam civili, promptam ma[174r]num habentes ad scribendum sermonem, quem ipse magister pronuntiabat, de verbo ad verbum tam in latino quam in vulgari integraliter scripserunt prefatos sermones plenos magna scientia, magnis auctoritatibus divine scripture, claros catholica doctrina fructuosa et salubri, sapida et redolenti mirabili movere corda et conscientias audientium, cuiuslibet etatis intelligibilis et cujuscumque status ecclesiastici vel mundani. Et dicte reportationes sive collecte sermonum predicti magistri Vincentii fuerunt ex post per multos scientificos transumptati sive scripti et ad diversas mundi partes transportati, et multi predicatores ex post usi sunt in predicationibus suis dictis sermonibus catholicis et excellentibus, et utuntur adhuc hodiernis temporibus ${ }^{75}$.

Del mismo modo que el arzobispo Bernardo de Rosier, otros muchos testigos se refirieron a la presencia de los reportadores entre los que asistían a la predicación del maestro; (2) Vicente Juan Marselli depuso: Item deponit ipse loquens quod multi erant scribentes suam predicationem seu verba sue predicationis $^{76}$; (3) el obispo Petrus Bonaldi expuso que

eamque plures viri theologi et juriste, et alii promptam manum habentes ac scribendum qui, secundum quod magister Vincentius predictus pronuntiabat, tam in latino quam in romantio, scribebant suos sermones ${ }^{77}$;

(4) el mercader Juan d'Avessano explicaba erantque multi valentes viri clerici utriusque juris, veloces manus ad scribendum habentes, qui reportabant suos sermones, ac verbo ipsius magistri Vincentii ad longum studebant ${ }^{78}$; (5) y, finalmente, también el presbítero Guillem Porta refiriéndose a la predicación llevada a cabo en Perpiñán y a los reportadores afirmó:

\footnotetext{
${ }^{73}$ Véanse las consideraciones de Martí de Riquer, Riquer, Comas, Molas 1984, pp. 396-401.

74 "Reverendus in Christo pater dominus Bernardus de Rosergio, archiepiscopus tholosanus, magister in theologia et utriusque juris doctor etatis ut dixit quinquaginta trium annorum", Valencia. Universitat de València. Biblioteca Histórica, ms. 690, f. 172|173r.

${ }^{75}$ Ibidem, ff. 172l173r - 173|174r; $c f$. Fages 1904, pp. 279-280; Brettle 1924, p. 79. Véase asimismo la versión castellana del mencionado texto en Proceso de Canonización, Fuster (trad.) 2007, pp. 30-31.

${ }^{76}$ Ibidem, f. 205v.

${ }^{77}$ Ibidem, f. 207v.

${ }^{78}$ Ibidem, f. $217 \mathrm{v}$.
} 


\begin{abstract}
Nam vidit idem testis loquens quod in dictis sermonibus, multi prelati, cardinales et alii, quia tunc temporis papa Benedictus tredecimus erat in villa Perpiniani pro unione fienda sancte matris Ecclesie, et vidit ipse testis loquens et audivit quod eius predicatio placebat multum audientibus, et multi audientes reportabant ejus sermonem et allegationes quas faciebat in suo sermone ${ }^{79}$.
\end{abstract}

¿Qué información aportan los manuscritos sobre los reportadores? Las reportaciones efectuadas por Friedrich von Amberg y por Antonio Anglada, así como la de los desconocidos copistas del manuscrito del Real Colegio y Seminario del Corpus Christi de Valencia, entre los que tal vez convenga considerar a Juan de Alcoy, proporcionan noticias de gran significado para conocer de qué modo trabajaban y actuaban los reportadores, tal y cómo se ha puesto de relieve en páginas anteriores. Se desconoce, en la actualidad, la materialidad de estos manuscritos en los que el reportans reelabora las notas que previamente tomó en el instante mismo de la homilía; quizá mostraban un aspecto similar al que exhibe el sermonario del Real Colegio y Seminario del Corpus Christi de Valencia.

El nombre y personalidad de los reportadores, en su mayoría, nos resultan completamente desconocidos, excepto los casos recordados de Antonio Anglada o Friedrich von Amberg. Tampoco son muy dados a facilitar referencias sobre su actividad, como con cierta frecuencia, los copistas aludían a la fatiga y el cansancio que les deparaba su trabajo, a las recompensas que esperaban alcanzar como premio a su entrega y dedicación, así como sus anhelos más íntimos ${ }^{80}$. Los reportadores complementan, ocasionalmente, algunas de las circunstancias referidas por el predicador. Conocida es la ocasión en la que anotó: Et ego, scriptor, vidi istud, cuando el dominico valenciano refirió un asunto maravilloso en los siguiente términos: A Nules, prop València, se n'entrà [s'enfonsà] bona part del cadafal, e havia gent damunt e davall, e no hi reberen mal degú ${ }^{81}$. En otra ocasión, el reportador anotó: A mi, scriptor,

\footnotetext{
${ }^{79} \mathrm{Ibidem}$, f. 242v. Todos los textos citados proceden como se ha indicado del manuscrito del proceso de canonización conservado en la Biblioteca Histórica de la Universitat de València, ms. 690. Dichos textos fueron publicados por Fages 1904, pp. 279-280, 332, 336, 352 y 362 y los menciona también J. Sanchis Sivera en el estudio introductorio de Ferrer, Quaresma, ed. Sanchis Sivera, 1927, pp. XXV-XXVI nota 2.

${ }^{80}$ Oportuna resulta en este sentido la lectura de los colofones de los manuscritos en los que se recogen todo este tipo de informaciones. Afortunadamente se dispone, al objeto de valorar este aspecto relativo a la mentalidad de los copistas, del repertorio elaborado por los Bénédictins du Bouveret 1965-1982.

${ }^{81}$ Cf. Chabás 1995, p. 229, nota 2; citado por Riquer, Comas, Molas 1984, pp. 400-401. Según Roque Chabás, la mencionada anotación se encontraba en el tomo IV, f. 218 de los volúmenes de sermones de san Vicente Ferrer custodiados en el Archivo de la Catedral; dicho manuscrito corresponde con la signatura actual 277, que desapareció durante la Guerra Civil.
} 
contengué que se'm féu quell mal; a dos dies lo haguífet secar ab la creu e ab lo nom de Jesús solament, una vez transcrita la curación milagrosa que había descrito con todo lujo de detalles Vicente Ferrer ${ }^{82}$. Finalmente, el reportador de la Cuaresma de 1413 anunciaba al lector su indisposición para escribir el viernes santo, justificando de ese modo la ausencia de la prédica de dicho día; dice así: Die veneris sancta non valui scribere propter fletum ${ }^{83}$.

\section{ORGANIZACIÓN TEMÁTICA DE LAS REPORTATIONES}

\subsection{Reportationes per circuli annum}

Además de los manuscritos de esquemas mencionados, como señala J. Perarnau i Espelt, se han conservado códices en los que se han organizado las reportationes atendiendo a la secuencia del año litúrgico, que él aglutinaba bajo el común denominador de "Reportationes per anni circulum vel partes eius dispositae" ${ }^{44}$. Destacan en este contexto las colecciones que recogen los sermones para el año litúrgico completo ${ }^{85}$. Sobresale entre todos los conservados el que transmite la conocida como la redacción tolosana, la cual organiza en dos volúmenes los sermones de tempore y los de sanctis para todo el año. Se trata de los manuscritos 345 y 346 de la Bibliothèque Municipale de Toulouse. El primero, es decir el número $345^{86}$, recoge la serie de sermones de tempore, entre el primero, en el que empleó el tema: Benedictus qui venit in nomine Domini ${ }^{87}$, Mt 21, 9, correspondiente al primer domingo de adviento ${ }^{88}$, y el propio de la "Dominica XXV" post Trinitatem sermo $2^{\text {us", }}$, cuyo tema fue: Ecce dies veniunt dicit Dominus, Ier 23, $5^{89}$. Prosiguen a continuación algunos sermones especiales tales como: de universali juicio ("Beatus ille servus cum venerit Dominus", Mt 24, 4690); de timore Domini ("Magnificavit eum in

\footnotetext{
${ }^{82}$ Valencia. Archivo de la Catedral, ms. 278, f. CXXv; $c f$. Chabás 1995, p. 230, citado por Riquer, Comas, Molas 1984, p. 401; edición íntegra del texto en Ferrer, Sermons, ed. G. Schib, 1975 , p. 304

${ }^{83}$ Valencia. Archivo de la Catedral, ms. 273, f. CCLXXXVIIIICCCXXIIIIr, $c f$. Ferrer, Quaresma, ed. Sanchis Sivera, 1927, p. 296.

${ }^{84}$ Cf. Perarnau 1999 e, p. 480.

${ }^{85}$ Cf. Kaeppeli, Panella 1993, n. ${ }^{\circ} 4027$, pp. 465-466. p. 200.

${ }^{86}$ Toulouse. Bibliothèque Municipale, ms. 345, cf. Catalogue Général, tome VII, 1885,

${ }^{87}$ Cf. Perarnau 1999e, n. ${ }^{\circ} 79$, pp. 508-509.

${ }^{88}$ Toulouse. Bibliothèque Municipale, ms. 345, f. 1r.

${ }^{89}$ Ibidem, f. 225v; $c f$. Perarnau 1999e, n. ${ }^{\circ} 209$, pp. 555-556.

${ }^{90}$ Ibidem, f. 227v; cf. Perarnau 1999e, n. ${ }^{\circ} 69$, p. 505.
} 
timore", Eccli 45, $2^{91}$ ); de virtute vigilancia ("Tu vero vigila in omnibus labora", 2 Tim 4, 592); de pace ("Pacem relinquo vobis, pacem meam do vobis", Io $14,27^{93}$ ), y de mandatis Dei ("Sicut mandatun dedit michi pater sic facio", Io $\left.14,31^{94}\right)$.

Otro manuscrito que se presenta próximo, en cuanto a su estructura, a la redacción tolosana es el 56-5-3195 de la Biblioteca Capitular y Colombina que transmite los sermones correspondientes al tiempo litúrgico que va desde Pascua (Sermo in die Pasche: "Surrexit, non est hic", Mc 16, 696), hasta el lunes posterior al domingo vigésimo quinto posterior a la Trinidad (Feria secuda eiusdem dominice: "Ecce dies veniunt", Ier 23, $5^{97}$ ). Se trata, en definitiva, de la pars aestivalis en la redacción que muestran los incunables; se desconoce en la actualidad el paradero del volumen primero, cuyo texto coincidiría con la pars hyemalis. El manuscrito incorpora, además, el índice de los sermones transcritos indicando el día y el tema predicado ${ }^{98}$ y una tabula con los temas tratados ordenada alfabéticamente ${ }^{99}$.

Los manuscritos 276, 278 y 279 del Archivo de la Catedral de Valencia presentan una secuencia incompleta del año litúrgico por la desaparición del ms. $277^{100}$ durante la guerra civil española. El ms. $276^{101}$ transcribe los sermones desde la Epifanía (In die Epiphanie: "Procidentes adoraverunt eum", Mt 2, $11^{102}$ ) hasta el martes posterior al quinto domingo después de Pascua, en el que se predicó el tema: "Omnis qui petit accipit", Lc 11, 10 ${ }^{103}$. El ms. $278^{104}$ transcribe los sermones correspondientes al tiempo que media entre san Lorenzo (De sancto Laurentio: "Multum fructum affert, qui amat animam suam", Io $12,25^{105}$ ) y el domingo vigésimo tercero después de Pentecostes [Dominica $X X I I I I^{a}$ (sic)]: "Serve nequam, omne debitum tibi dimisum quoniam rogasti

${ }^{91}$ Ibidem, ff. 229v; cf. Perarnau 1999e, n. ${ }^{\circ} 497$, pp. 656-657.

${ }^{92}$ Ibidem, ff. 232v; $c f$. Perarnau 1999e, n. ${ }^{\circ} 842$, pp. 780-781.

${ }^{93}$ Ibidem, ff. 233v; cf. Perarnau 1999e, n. ${ }^{\circ} 632$, pp. 706- 707.

${ }^{94}$ Ibidem, ff. 235v; $c f$. Perarnau 1999e, n. ${ }^{\circ} 795$, p. 764.

${ }^{95}$ Sevilla. Biblioteca Capitular y Colombina, ms. 56-5-31, f. 1r; Álvarez 1999, pp. 127-128.

${ }^{96}$ Ibidem; cf. Perarnau 1999e, n. ${ }^{\circ} 827$, pp. 774-775.

${ }^{97}$ Sevilla. Biblioteca Capitular y Colombina, ms. 56-5-31, f. 229v; $c f$. Perarnau 1999e, n. ${ }^{\circ} 209$, pp. 555-556.

${ }^{98}$ Ibidem, ff. 333r-334v.

${ }^{99}$ Ibidem, ff. 342r.

${ }^{100}$ Valencia. Archivo de la Catedral, ms. 277, cf. Olmos 1943, p. 201.

${ }^{101}$ Valencia. Archivo de la Catedral, ms. 276, cf. Olmos 1943, pp. 200-201.

${ }^{102}$ Ibidem, f. 1r, cf. Perarnau 1999e, n. ${ }^{\circ}$ 667-668, pp. 720-721.

${ }^{103}$ Ibidem, f. 237r, cf. Perarnau 1999e, n. ${ }^{\circ}$ 616, pp. 700-701.

${ }^{104}$ Valencia. Archivo de la Catedral, ms. 278, f. 1r; $c f$. Olmos 1943, pp. 201-202.

${ }^{105}$ Ibidem; cf. Perarnau 1999e, n. ${ }^{\circ}$ 541, p. 671. 
me", Mt 18, 32 $2^{106}$ ). Finalmente, en el ms. $279^{107}$ se transcriben los sermones correspondientes al tiempo litúrgico que media entre la vigilia de la Ascensión (In vigilia ascensionis Domini, id est Chriti: "Sublevatis Jhesus oculis in celum, dixit", Io $17,1^{108}$ ) y el martes posterior al décimo domingo después de la Trinidad (Feria III [post dominica $X^{a}$ post Trinitatem]: "Per spiritum datur generacio virtutum", 1 Cor $\left.12,10^{109}\right)$.

J. Perarnau ${ }^{110}$, basándose en Brettle, refiere la existencia de otros manuscritos con la redacción completa del año litúrgico, concretamente los conservados en Friburgo (Couvent des Cordeliers ms. 68); Basilea, Einsiedeln, Engelberg y Leipzig ${ }^{111}$.

\subsection{Sermones de sanctis}

La redacción tolosana destinaba el segundo volumen, es decir el códice Toulouse. Bibliothèque Municipale 346, a los sermones de sanctis ${ }^{112}$. El manuscrito comienza con el sermón dedicado a san Andrés (In festo sancti Andree sermo: "Dives est in omnes qui invocant illum", Rom 10, 12113), y finaliza la serie de sanctis con el de la festividad de santa Catalina (In festo beate Catherine virginis: "Profert de thesauro nova et vetera", Mt 13, 52 $\left.{ }^{114}\right)$. Continúan 23 sermones dedicados al propio de los santos, a diversos días de la semana y festividades, y aborda en otros asuntos de moralidad y religión ${ }^{115}$. Igualmente, el ms. 274 del Archivo de la catedral de Valencia transcribe un volumen de sanctis ${ }^{116}$, el cual comienza igualmente con la festividad de san Andrés ${ }^{117}$ y finaliza con el dedicado a santa Catalina ${ }^{118}$. Se han incorporado, además, los sermones de san Matías (De sancto Mathia sermo: "Cecidit sors super Mathiam", Act 1, 26 ${ }^{119}$ ), san Gregorio (De festo beati Gregorii: "Quis

\footnotetext{
${ }^{106}$ Ibidem, f. 252r, cf. Perarnau 1999e, n..$^{\circ} 776$, p. 758.

${ }^{107}$ Valencia. Archivo de la Catedral, ms. 279, cf. Olmos 1943, pp. 202.

${ }^{108}$ Ibidem, f. 1r; $c f$. Perarnau 1999e, n. ${ }^{\circ} 820$, p. 771-772.

${ }^{109}$ Ibidem, f. 277r, cf. Perarnau 1999e, n. ${ }^{\circ} 649$, p. 713.

${ }^{110} \mathrm{Cf}$. Perarnau 1999e, p. 480, apartado F.

${ }^{111} C f$. Brettle 1924, p. 91; véase también Kaeppelli, Panella 1993, n. ${ }^{\circ}$ 4027, pp. 465-466.

${ }^{112}$ Toulouse. Bibliothèque Municipale, ms. 346 ; $c f$. Catalogue Général, tome VII, 1885,

${ }^{113}$ Ibidem, ff.1r; $c f$. Perarnau 1999e, n. ${ }^{\circ} 181-182$, pp. 546-547.

${ }^{114}$ Ibidem, ff. 179r; $c f$. Perarnau 1999e, n. ${ }^{\circ} 670$, p. 721.

115 Ibidem, ff. 182r-210v.

${ }_{116}$ Valencia. Archivo de la Catedral, ms. 274; $c f$. Olmos 1943, pp. 199-200.

${ }^{117}$ Ibidem, f. $1 \mathrm{r}$.

${ }^{118}$ Ibidem, f. 283v.

${ }^{119}$ Ibidem, f. 290v.
} p. 200. 
putas est fidelis servus et prudens", Mt 24, $45^{120}$ ), y san Juan Bautista (In nativitate beati Iohannis babtiste: "Non surrexit maior Iohanne inter natos mulierum", Mt $1^{\circ}$, Lc $7^{121}$ ). Finaliza en el f. 296v con: Explicit sanctorale compositum per magistrum Vincencium Ferrarii.

\subsection{Sermones quadragesimales}

Un grupo importante de manuscritos lo constituyen los dedicados a transmitir los sermones correspondientes al tiempo de Cuaresma ${ }^{122}$. Entre los que recogen series de este tiempo litúrgico pueden recordarse los siguientes: el ms. Friburgo. Couvent des Cordeliers, ms. 62, el cual transmite los sermones pronunciados entre el domingo 9 de marzo (Dominica Letare, in Friburgo, anno Domini $M^{o} C C C C^{o} I I I I^{o}$ : "Oracio enim humilitatis se nubes penetrat", Eccli $35,21^{123}$ ) y el viernes anterior al domingo de ramos, es decir el 21 de marzo de 1404 (Feria sexta ante dominicam Palmarum, in Staviaco. Ad populum, ante prandium. "Sana me, Domine, et sanabor", Ier 17, 14 ${ }^{124}$ ). La serie de sermones cuaresmales, en este manuscrito, es incompleta. Friedrich von Amberg transcribió, en total, dieciséis de los sermones predicados por san Vicente Ferrer en tierras helvéticas. De los dieciséis, cinco los pronunció en Friburgo (números 1 a 5); dos en Murten (n. ${ }^{\circ}$ 6,7); dos en Payerne (n. $\left..^{\circ}, 9\right)$; dos en Avenches (n. ${ }^{\circ} 10,11$ ) y cinco en Estavayerle-Lac (números 12 a 16). Llama la atención la frenética actividad llevada a cabo por el dominico valenciano en algunas ocasiones como el jueves 20 y el viernes 21 de marzo, ya que el primer día predicó tres veces en Estavayer-le-Lac ${ }^{125}$, y la segunda jornada lo hizo también en la misma localidad en dos ocasiones ${ }^{126}$.

${ }^{120}$ Ibidem, f. 292v.

${ }^{121}$ Ibidem, f. 294r. Adviértanse, según la Vulgata, las diferencias textuales de los pasajes citados con el tema transcrito. Mt 11, 11: "non surrexit inter natos mulierum major Johanne Baptista"; Lc 7, 28: "major inter natos mulierum propheta Johanne Baptista nemo est".

${ }^{122} C f$. Kaeppeli, Panella 1993, n. ${ }^{\circ}$ 4024, p. 464.

${ }^{123}$ Friburgo (Suiza). Couvent des Cordeliers, ms. 62, f. 46r; $c f$. Ferrer, Sermones, ed. Gimeno, Mandingorra, 2009, p. 47 y ss.; Perarnau 1999 e, n. ${ }^{\circ} 625$, p. 704.

${ }^{124}$ Ibidem, f. 93r; cf. Ferrer, Sermones, ed. Gimeno, Mandingorra, 2009, p. 141; Perarnau 1999 e, n. ${ }^{\circ} 764$, p. 753.

${ }^{125}$ Ad populum. "Remittuntut tibi peccata", Lc 7, 48, cf. Ferrer, Sermones, ed. Gimeno, Mandingorra, 2009, sermón 12, pp. 121-126); Ante prandium. Ad clerum. "Morabatur Iesus cum discipulis suis", Io 11, 54, cf. Ferrer, Sermones, ed. Gimeno, Mandingorra, 2009, sermón 13, pp. 127-131); Post prandium. Monialibus. "Sequimur te, Domine, in toto corde nostro", Dan 3, 41, cf. Ferrer, Sermones, ed. Gimeno, Mandingorra, 2009, sermón 14, pp. 133-136).

${ }^{126}$ Post prandium. Monialibus: "Sicut lucerna fulgoris illuminabit te", Lc 11, 36, cf. Ferrer, Sermones, ed. Gimeno, Mandingorra, 2009, sermón 15, pp. 137-139); Ante prandium. Ad populum: "Sana me, Domine, et sanabor", Ier 17, 14, cf. Ferrer, Sermones, ed. Gimeno, Mandingorra, 2009, sermón 16, pp. 141-145). 
El ms. Sevilla. Biblioteca Capitular y Colombina, ms. 56-5-32 $2^{127}$ comienza con: Incipiunt sermones quadragesimales domini fratris Vincencii de ordine predicatorum; incluye los sermones cuaresmales a partir del miércoles de ceniza ("Cum jejunas unge caput tuum et faciem tuam lava", Mt 6, 17 ${ }^{128}$ ), y finaliza con el sermón del miércoles posterior al domingo de ramos en el que utilizó el tema: "Propter zelus populi", Is 53, $8^{129}$. El ms. 45 de la Biblioteca municipal de Clermont-Ferrand (Incipiunt sermones totius $X L^{e 130}$ ), comienza con el sermón predicado el martes previo al miércoles de ceniza (Et primo sermo factus in die martis carnisprevii per magistrum Vincentium Ferrerii ${ }^{131}$ ) sirviéndose del tema: "Acheldamac, hoc est, ager sanguinis", Act 1, 19"132; finaliza con el sermo mercurii sancta, en el que empleó el tema: "Domine, memento mei dum veneris in regnum tuum", Lc 23, $47^{133}$.

El manuscrito II/413 de la Real Biblioteca de Madrid transmite un Quadragesimale beati Vincentii ${ }^{134}$. En realidad se trata de una compilación miscelánea de sermones en la que se incluye no solo la cuaresma, sino también otros pronunciados a lo largo del año. Comienza la serie de cuaresma en el f. 1r: Incipit quadragesimale beati Vincentii, con el sermón del miércoles de ceniza ("Cum ieiunas unge caput tuum et faciem tuam lava", Mt 6, 17), y finaliza en el f. 97r con: Explicit quadragesimale sancti Vincencii ordinis fratrum predicatorum, una vez finalizado el Sermo VII ${ }^{u s}$. "Stetit Jhesus in medio discipulorum suorum", Io 20, 19 ${ }^{135}$. Continúan la segunda serie (Sermones a dominica prima post octavas Pasce $\left.{ }^{136}\right)$, la cual finaliza: Expliciunt sermones beati Vincentii ordinis fratrum predicatorum a dominica prima post octavas Pasche usque ad dominicam primam post Trinitatem ${ }^{137}$; la tercera: Sermones a dominica prima post Trinitatem usque ad dominicam XIII post Trinitatem ${ }^{138}$, y la cuarta: Sermones a dominica XIII post Pentecosten et XIV post Trinitatem usque ad dominicam XXV post Pentecosten et XXIV post Trinitatem ${ }^{139}$.

${ }^{127}$ Cf. Álvarez 1999, pp. 129-130.

${ }^{128}$ Sevilla. Biblioteca Capitular y Colombina, ms. 56-5-32, f. 1r; Perarnau 1999e, n. ${ }^{\circ} 137$, pp. 531-532.

${ }^{129}$ Ibidem, f. 113v; Perarnau 1999e, n. ${ }^{\circ} 675$, p. 723.

${ }^{130}$ Consultado en la versión digital: http://bvmm.irht.cnrs.fr/consult [consulta: 03/07/2018].

${ }^{131}$ Clermont-Ferrand. Bibliothèque Municipale, ms. 45, f. 1r.

${ }^{132}$ Ibidem, f. 1r ; Perarnau 1999e, n. ${ }^{\circ} 15$, p. 486.

${ }^{133}$ Ibidem, f. 161l153v; Perarnau 1999e, n. ${ }^{\circ} 191$, p. 550.

${ }^{134}$ Madrid. Palacio Real. Real Biblioteca, ms. II/413, cf. López 1994, pp. 119-120.

${ }^{135}$ Ibidem, f. 96v; $c f$. Perarnau 1999e, n. ${ }^{\circ} 817$, pp. 770-771.

${ }^{136}$ Ibidem, f. 97 r.

${ }^{137}$ Ibidem, f. 151r.

${ }^{138}$ Ibidem, f. 151v.

${ }^{139}$ Ibidem, f. 217 r. 
El manuscrito $273^{140}$ del Archivo de la Catedral de Valencia transcribe un total de cincuenta y cuatro sermones, correspondientes al tiempo cuaresmal del año 1413. La serie da comienzo la "Dominica in L", es decir el domingo de quinquagésima, que el año 1413 coincidió con el 5 de marzo y predicó el tema: "Omnis plebs vidit et dedit laudem Deo", Lc 18, 43; concluye la serie con el sermón 53 correspondiente al miércoles 26 de abril, feria IV después del domingo de Pascua ("Manifestatus est Jhesus discipulis suis", Io 21, 14). De la serie transcrita tan solo falta el sermón del viernes santo, número 48, en su lugar el copista anotó: "Die veneris sancta non valui scribere sermonem propter fletum"141, ya mencionado. Recuérdese el sermonario del archivo parroquial de Ayora, de cuyo contenido y circunstancias materiales se informa en el apartado siguiente.

No deben de olvidarse en este recorrido sumario sobre la tradición de los sermones de Vicente Ferrer, las colecciones estrechamente ligadas a una campaña de predicación como la llevada a cabo por tierras de Castilla entre 1410-1412, como testimonian el manuscrito del Real Colegio y Seminario del Corpus Christi de Valencia ${ }^{142}$, en el que se recogen los sermones predicados por tierras castellanas entre el 15 de febrero de 1411( [Dominica in sexagessima] ${ }^{143}$ ) y el 22 de enero de 1412, festividad de san Vicente mártir (Feria VI ${ }^{a}$, festum beati Vincenti martiris $\left.{ }^{144}\right)$. El manuscrito 294 Real Academia Española ${ }^{145}$, transmite parcialmente la predicación castellana, se trata de una copia datada según informa el colofón del mismo:

Acabado fue este libro en la casa de oración del señor Sant Andrés de San Pedro de Latarza, a treynta días del mes de agosto, año del nasçimiento del nuestro señor e salvador Jhesuchristo de mill e quatroçientos e quarenta e ocho años. Rogad a Dios por quyen lo escribió, assí como queríades que rrogassen por vos.

Facta fuyt liber iste pro mandacto Antonii Roderici, cure loci sopraditi, cuius est liber ${ }^{146}$.

\footnotetext{
${ }^{140}$ Valencia. Archivo de la Catedral, ms. 273, cf. la descripción en Olmos 1943, pp. 198-199; la edición del texto en Ferrer, Quaresma, ed. Sanchis Sivera, 1927 (una edición actualizada en Ferrer, Sermons, ed. Sanchis Sivera, 1973). p. 296.

${ }^{141}$ Ibidem, f. CCLXXXVIIIICCCXXIIIIr; $c f$. Ferrer, Quaresma, ed. Sanchis Sivera, 1927,

${ }^{142}$ Cf. Ferrer, Sermonario de San Vicente Ferrer, ed. Gimeno, Mandingorra, 2002; Cátedra 1994, pp. 36-73.

${ }^{143}$ Ferrer, Sermonario de San Vicente Ferrer, ed. Gimeno, Mandingorra, 2002, pp. 31-32; Cátedra 1994, p. 37.

${ }^{144}$ Ferrer, Sermonario de San Vicente Ferrer, ed. Gimeno, Mandingorra, 2002, pp. 818-824; Cátedra 1994, p. 73.

${ }^{145}$ Cf. Catálogo 1991, pp. 269-270; Cátedra 1994, pp. 29-35 y edición íntegra del texto en pp. 277-662.

${ }^{146}$ Madrid. Real Academia Española, ms. 294, f. 178r; según la transcripción publicada por Cátedra 1994, p. 662.
} 
De la predicación llevada a cabo en Mallorca entre septiembre de 1413 y enero de 1414, informa el ms. 610 de la Biblioteca Municipal de Aviñón, ya comentado; el manuscrito 477 de la Biblioteca de Cataluña en Barcelona recoge sermones predicados a lo largo del viaje de Valencia a Barcelona, realizado entre los meses de abril y agosto del año $1413^{147}$.

Quisiera, para finalizar este elenco de manuscritos señalar una colección custodiada por el Archivo de la Catedral de Valencia, el ms. $168^{148}$, y que el compilador designó como sermones dominicales según el íncipit, que reza del siguiente modo: Incipiunt sermones dominicales recollecte per magistrum Vincentium Ferrarii, de bona memoria, per totum annum ${ }^{149}$. Comienza con el sermón: "Ille arguet mundum de peccato", Io $16,8^{150}$, correspondiente al tercer domingo después de la octava de Pascua, y finaliza con la homilía en la que utilizó el tema: "Tempus mee resolutionis instat", 2 Tim 4, 6 ${ }^{151}$, predicado en ocasiones en la semana post dominicam XXV post Pentecosten ${ }^{152}$.

\section{MANUSCRITOS COPIADOS POST MORTEM. DOS TESTIMONIOS DATADOS}

La fama alcanzada por Vicente Ferrer como predicador hizo que, después de su óbito, ocurrido el 5 de abril de 1419, continuarán realizándose ediciones manuscritas de sus sermones. El contenido textual de todas ellas no siempre resulta ser la misma, como sucede por ejemplo con los manuscritos datados conservados en el archivo parroquial de Ayora ${ }^{153}$ y en la Biblioteca Capitular y Colombina de Sevilla ${ }^{154}$. La compilación de Ayora fue copiada por el notario apostólico Matheus Xivelli, como recuerda el colofón, de 7 de marzo de 1435:

Laus de terrenis debetur gloria celis. Fuerunt sermones supradicti die septima mensis marcii anni nativitatis Domini millesimi $\mathrm{CCCC}^{\mathrm{i}}$ tricesimi quinque per manum Mathei Xivelli, auctoritate apostolica notarii, scrcipti et completi. Deo gracias. Amen ${ }^{155}$.

${ }^{147}$ Cf. Perarnau 1974; 1985.

${ }^{148}$ Cf. Olmos 1943, n. ${ }^{\circ} 168$, p. 126.

${ }^{149}$ Valencia. Archivo de la Catedral, ms. 168, f. 1r.

${ }^{150}$ Cf. Perarnau 1999e, n. ${ }^{\circ} 421$, p. 630.

${ }^{151}$ Valencia. Archivo de la Catedral, ms. 168, f. 336r; cf. Perarnau 1999e, n. ${ }^{\circ} 830$, p. 776.

${ }^{152}$ Cf. Perarnau 1999e, n. ${ }^{\circ} 830$, p. 776.

${ }^{153}$ Cf. Ferrer, Colección de sermones, ed. Robles Sierra, 1995.

${ }^{154}$ Sevilla. Biblioteca Capitular y Colombina, ms. 56-5-31. Véase. la descripción en Álvarez 1999, pp. 127-128.

${ }^{155}$ Ayora. Archivo parroquial. Sermonario de san Vicente Ferrer, f. CLXXIv (Ferrer, Colección de sermones, ed. Robles Sierra, 1995, p. 490). 
La colección de Ayora transcribe un total de cincuenta y tres sermones organizados, según el editor, en cuatro bloques. Al primero corresponden los sermones de los domingos de cuaresma, el domingo de pasión, domingo de ramos, jueves santo, dominica in $L X^{a}$, dominica in quinquagesima, martes carnisprevii, y capite ieiunii. El segundo bloque incluye la cuaresma predicada en Lérida el año 1414, según advierte el propio manuscrito ${ }^{156}$; se incluyen los sermones predicados entre el dos de marzo y el tres de abril de 1414, es decir desde el viernes previo al segundo domingo de cuaresma hasta el martes santo. El tercer bloque incorpora sermones de la cuaresma de 1413, desde el sermo factus Valencie feria $V^{a}$ in die cene Domini ${ }^{157}$ hasta el sermo factus Valencie feria IIII $^{a}$ post Pascha, est ultimus ibi factus ${ }^{158}$. Y, finalmente, el cuarto transcribe una selección de sermones comenzando por el sermo factus in civitate Maioricarum, et est de vita Christi representata in missa solem$n i^{159}$, continúa una selección de sermones de santos, comenzando el día de san Francisco de Asís y finalizando la festividad de santa Catalina; concluye esta serie con dos sermones del domingo de ramos ${ }^{160}$.

La Biblioteca Capitular y Colombina de Sevilla, como se ha anunciado, conserva entre sus manuscritos una edición de la pars aestivalis de los sermones de tempore datada el 12 de diciembre del año 1432, según anuncia el colofón:

Hii sermones a dominica in Trinitate usque ad adventum sunt magistri Vincentii Ferrarii, effective quos scripsit et cetera, et fuerunt completi $12^{\mathrm{a}}$ decembris anni Domini 1432. Deo gratias. Amen $^{161}$.

Adviértase, que el colofón sitúa el inicio del recorrido textual en el domingo de la Trinidad, lo que ciertamente constituye un lapsus calami en la medida en que el manuscrito comienza con el sermón coincidente con el domingo de resurrección, como proclaman una rúbrica añadida con posterioridad a la escritura del manuscrito, Sermo in die Pasche, y el tema del día: "Surrexit non est hic", Mc 16, $6^{162}$. Los sermones transcritos recorren todo el

\footnotetext{
${ }^{156}$ Ibidem, f. LXVIIIr (Ferrer, Colección de sermones, ed. Robles Sierra, 1995, p. 157).

${ }^{157}$ Ibidem, f. CLXXVIIv (Ferrer, Colección de sermones, ed. Robles Sierra, 1995, p. 333).

${ }^{158}$ Ibidem, f. CCXIv (Ferrer, Colección de sermones, ed. Robles Sierra, 1995, p. 388).

${ }^{159}$ Ibidem, f. CCXVIr (Ferrer, Colección de sermones, ed. Robles Sierra, 1995, p. 397 y ss.)

${ }^{160}$ Ibidem, f. CCLXVIr (Ferrer, Colección de sermones, ed. Robles Sierra, 1995, p. 482 y ss.).

${ }^{161}$ Sevilla. Biblioteca Capitular y Colombina, ms. 56-5-31, f. 231v.

${ }^{162}$ Ibidem, f. 1r; cf. Perarnau 1999e, n. ${ }^{\circ} 827$, pp. 774-775.
} 
ciclo litúrgico hasta la feria secunda eiusdem dominice ${ }^{163}$, en el que predicó el tema: "Ecce, dies veniunt, dicit Dominus" 164.

El manuscrito incluye, una vez finalizada la transcripción, un índi$\mathrm{ce}^{165}$ con los temas predicados y la festividad correspondiente. Finaliza el manuscrito con un listado de materias, como las que aparecen, posteriormente, en todos los incunables. Esta tabula ordenada alfabéticamente, finaliza con el siguiente texto:

Istam tabulam ordinavit frater Mundonus Belvayleti, sacre theologie humilis magister, licet subitatus secundum naturam vocalitatum et ordinare non potuerimus. Ora Deum pro illo. Amen ${ }^{166}$.

Mundonus Belvayleti fue, quizá, el comitente de este manuscrito, relación a la que se alude en la rúbrica del comienzo en la que se lee:

Secuntur aliqui sermones gloriosissimi patris fratris Vincencii Ferrarii sacre theologie magistri famosissimi, ordinis fratrum predicatorum provincie Arogonie conventus valentinensis cuius benedictam animam michi fratri Mundono Belvayleti protectricem constituo coram tremendo iudice mortis in articulo ${ }^{167}$.

En realidad, el autor de la tabula y, tal vez, de la compilación es Mundonus Belvaylleti, del que se dispone de muy poca información de carácter biográfico; el apellido, no obstante, como recuerda el Bullarium Ordinis Praedicatorum es Beauvillier ${ }^{168}$. Mundon Beauvilier, capellán y penitenciero del papa Eugenio IV, fue elegido el 9 de noviembre de 1443 prior del monasterio de Saint-Germain-en-Brionnais.

Los manuscritos datados comentados no constituyen los únicos testimonios que ponen al descubierto el interés que suscitó la predicación vicentina antes y después de su canonización el 29 de junio de $1455^{169}$. En la actualidad no existe todavía un listado completo de los manuscritos que transmiten los sermones de Vicente Ferrer. Th. Kaeppeli y E. Panella ${ }^{170}$, como se ha señalado, proporcionan un elenco importante de los manuscritos distribuidos

\footnotetext{
${ }^{163}$ Ibidem, f. 329r.

${ }^{164}$ Ibidem, f. 329v; cf. Perarnau 1999e, n. ${ }^{\circ} 209$, pp. 555-556.

${ }^{165}$ Ibidem, ff. 333r-334v.

${ }^{166}$ Ibidem, f. 342r.

${ }^{167}$ Ibidem, f. $1 \mathrm{r}$.

${ }^{168}$ Cf. Bullarium Ordinis 1731, p. 52.

${ }^{169}$ Cf. Antist 1575; Garganta, Forcada 1956, pp. 316-320.

${ }^{170}$ Cf. Kaeppeli, Panella 1993, pp. 458-474, especialmente los registros 4019, 4021, 4023, 4024, 4025, 4027, 4028, 4029, 4030, 4031, 4032, 4033.
} 
atendiendo a los diferentes argumentos abordados en los mismos. Falta, no obstante, la relación de los sermones que contienen cada uno de los códices reseñados. Sin duda un inventario de este tipo completaría definitivamente el listado de temas bíblicos publicado por Perarnau i Espelt ${ }^{171}$. Se echa de menos un catálogo en el que se detallen los manuscritos conservados, la secuencia litúrgica de los sermones transcritos, el tema bíblico predicado y la divisio thematis correspondiente. Sin lugar a dudas un repertorio que presente estas características constituirá una aportación significativa al conocimiento de la predicación de san Vicente Ferrer.

\section{FUENTES}

\section{BIBLIOGRAFÍA CITADA}

Ferrer, Vicent, Quaresma de sant Vicent Ferrer predicada a València l'any 1413 , introducción, notas y transcripción por J. Sanchis Sivera, Barcelona, Institució Patxot, 1927.

Ferrer, Vicent, Sermons de Quaresma, ed. Manuel Sanchis Guarner, 2 vols, Valencia, Albatros, 1973.

Ferrer, Vicent, Sermons, ed. Gret Schib, vol. III, Barcelona, Barcino, 1975.

Ferrer, Vicent, Colección de sermones de Cuaresma y otros según el manuscrito de Ayora, ed. Adolfo Robles Sierra, Valencia, Ayuntamiento de Valencia, 1995.

Ferrer, Vicent, Sermonario de San Vicente Ferrer del Real Seminario del Corpus Christi de Valencia, ed. Francisco M. Gimeno Blay, María Luz Mandingorra Llavata, Valencia, Ajuntament de València, 2002.

Ferrer, Vicent, Sermonario de Perugia (Convento dei domenicani, ms. 477), ed. Francisco M. Gimeno Blay, María Luz Mandingorra Llavata, trad. de D. Gozalbo Gimeno, Valencia, Ayuntamiento de Valencia, 2006.

Ferrer, Vicent, Sermones de cuaresma en Suiza, 1404 (Couvent des Cordeliers, ms. 62), ed. Francisco M. Gimeno Blay, María Luz Mandingorra Llavata, trad. castellana a cargo de Daniel Gozalbo Gimeno, Valencia, Ayuntamiento de Valencia, 2009.

Ferrer, Vicent (en prensa), Sermonario de Aviñón (Avignon. Bibliothèque municipales ms. 610), introducción, edición y notas a cargo de Francisco M. Gimeno Blay, María Luz Mandingorra Llavata.

${ }^{171} C f$. Perarnau 1999e. 


\section{ESTUDIOS Y OBRAS DE REFERENCIA}

Alcover, Antonio Maria (1980), Diccionari Català-Valencià-Balear, Tom IX: $Q$-Son, Palma de Mallorca, editorial Moll.

Álvarez Márquez, María del Carmen (1999), Manuscritos localizados de Pedro Gómez Barroso y Juan de Cervantes, arzobispos de Sevilla, Alcalá de Henares, Universidad - Diputación Provincial de Sevilla.

Antist, Vicente Justianiano (1575), La vida y historia del apostólico predicador san Vicente Ferrer, valenciano, de la orden de sancto Domingo, Valencia, en casa de Pedro de Huete [El contenido íntegro de esta biografía se reprodujo en Garganta, Forcada 1956, pp. 94-334, y Esponera Cerdán 2005a, pp. 153-479].

Antist, Vicente Justiniano (comp.) (1591) Sancti patris nostri Vincentii Ferrarii, valentini, ordinis praedicatorum opuscula a fratre ... sacrae theologiae doctore collecta et scholiis explicata, Valentiae, apud Petrum Patricium.

Bénédictins du Bouveret (1965-1982), Colophons de manuscrits occidentaux des origines au $X V I^{e}$ siècle, 6 vols., Friburgo, Éditions Universitaires Fribourg.

Brettle, Sigimund (1924), San Vicente Ferrer und sein literarischer Nachlass, Münster in Westfalen, Verlag der Aschendorffschen Verlagsbuchhandlung

Bullarium ordinis fratrum praedicatorum sub auspiciis SS. D. N. D. Clementis XII pontificis maximi opera reverendissimi patris $\mathrm{f}$. Thomae $\mathrm{Ri}-$ poll magistri generalis editum ... a p. F. Antonino Bremond. Tomus tertius ab anno 1430 ad 1484, Romae, Ex typographia Hieronymi Mainardi, 1731.

Cappelli, Adriano (1978), Cronologia, cronografia e calendario perpetuo, Milán, Ulrico Hoepli ( $4^{\mathrm{a}}$ ed.).

Catálogo de manuscritos de la Real Academia Española, Madrid, Real Academia Española, 1991.

Catalogue Général des manuscrits des bibliothèques publiques des départements, Tome VII (Toulouse/Nîmes), París, Imprimerie nationale, 1885.

Catalogue Général des manuscrits des bibliothèques publiques de France. Départements, Tome XXVII (Avignon), par Léon - Honoré Labande, París, Librairie Plon, 1894.

Cátedra, Pedro Manuel (1983-1984), La predicación castellana de San Vicente Ferrer, "Boletín de la Real Academia de Buenas Letras de Barcelona" 39, pp. 235-309.

Cátedra, Pedro Manuel (1994), Sermón, sociedad y literatura en la Edad Media. San Vicente en Castilla (1411-1412). Estudio bibliográfico, 
literario y edición de los textos inéditos, Salamanca, Junta de Castilla y León.

Colli, Vincenzo (1990), Termini del diritto civile, en Weijers, Olga (ed.), Méthodes et instruments du travail intellectuel au moyen âge, Turnhout, Brepols, pp. 231-242.

Chabás, Roque (1995), Estudio sobre los sermones valencianos de san Vicente Ferrer, que se conservan manuscritos en la biblioteca metropolitana de Valencia, en Chabás, Roque, Opúsculos, introducción de M. Rodrigo Lizondo, Valencia, Consell Valencià de Cultura, pp. 221-329.

Destrez, Jean (1935), La pecia dans les manuscrits universitaires du XIII e et du XIV siècles, París, Éditions Jacques Vautrain.

Du Cange (1954), Glossarium mediae et infimae latinitatis, Unveränderter Nachdruck der Ausgabe von 1883-1887, VII Band, Graz, Akademische Druck - U. Verlagsanstalt.

Esponera Cerdán, Alfonso (ed.) (2005a), San Vicente Ferrer. Vida y escritos, Madrid, Edibesa.

Esponera Cerdán, Alfonso (2005b), "Hi era ab la ajuda de Déu a ops de las ànimas molt profitós". San Vicente Ferrer en Mallorca, "Escritos del Vedat" 35, pp. 89-125.

Eubel, Conradum (1913), Hierarchia catholica medii aevi sive summorum Pontificum, S. R. E. cardinalium, ecclesiarum antistitum series ab anno 1198 usque ad annum 1431 perducta, Monasterii, Sumptibus et typis librariae Regensbergianae.

Fages, Pierre-Henri (1903), Historia de san Vicente Ferrer, trad. Antonio Polo de Bernabé, 2 vols, Valencia, A. García editor.

Fages, Pierre-Henri (1904), Procès de la canonisation de saint Vincent Ferrier, París, A. Picard.

Fuster Perelló, Sebastian (trad.) (2007), Proceso de canonización de San Vicente Ferrer, Valencia, Ajuntament.

Gams, Pius Bonifacius (1957), Series episcoporum ecclesiae catholicae, Graz, Akademische Druck - U. Verlagsanstalt.

Garganta, José M. de; Forcada, Vicente (dirs.) (1956), Biografía y escritos de san Vicente Ferrer, Madrid, La Editorial Católica.

Gutiérrez del Caño, Marcelino (1913), Catálogo de los manuscritos existentes en la Biblioteca Universitaria de Valencia, 3 vols., Valencia, Librería Maraguat.

Hamesse, Jacqueline (1988), “Collatio" et "reportatio". Deux vocables specifiques de la vie intellectuelle au Moyen Âge, en Weijers, Olga (ed), Terminologie de la vie intellectuelle au Moyen Âge, Turnhout, Brepols, pp. 78-87.

Hodel, Paul-Bernard (1993), Sermons de saint Vincent Ferrier à Estavayer-leLac en mars 1404, "Mémoire dominicaine" 2, pp. 149-192. 
Hodel, Paul-Bernard (2006), D'une édition a l'autre. La lettre de saint Vincent Ferrier à Jean de Puynoix du 17 décembre 1403, en Hodel, PaulBernard; Morenzoni, Franco (eds.), Mirificus praedicator, Roma, Istituto Storico Domenicano, pp. 189-203.

Jörg, Christoph (1975), Untersuchungen zur Büchersammlung Friedrichs von Amberg. Ein Beitrag zur franzikanischen Geistesgeschichte des Spätmittelalters, Friburgo, Paulusdruckerei.

Kaeppeli, Thomas; Panella, Emilio (1993), Scriptores Ordinis Praedicatorum Medii Aevi, vol. IV: T-Z, Roma, Istituto Storico Domenicano.

López Vidriero, María Luisa (dir.) (1994), Catálogo de la Real Biblioteca. Tomo XI: Manuscritos, vol. I, Madrid, Patrimonio Nacional.

Martínez Ferrando, Jesús Ernesto (1952), El nostre sant Vicent Ferrer, Valencia, Editorial Torre.

Martínez Ferrando, Jesús Ernesto (1955), San Vicente Ferrer y la Casa Real de Aragón. (Documentación conservada en el Archivo Real de Barcelona), Barcelona, CSIC - Balmesiana (Biblioteca Balmes).

Olmos y Canalda, Elías (1943), Códices de la catedral de Valencia, Segunda edición refundida y notablemente aumentada, Valencia, CSIC.

Pasquali, Giorgio (1988), Storia della tradizione e critica del testo, Florencia, Le Lettere.

Perarnau i Espelt, Josep (1974), Sermones de san Vicente Ferrer en los manuscritos de Barcelona, Biblioteca de Cataluña, 477, y Avignon, Musee Calvet, 610, "Escritos del Vedat" 4, pp. 611-646.

Perarnau i Espelt, Josep (1985), La compilació de sermons de sant Vicent Ferrer de Barcelona, Biblioteca de Catalunya ms. 477, "Arxiu de Textos Catalans Antics" 4, pp. 231-402.

Perarnau i Espelt, Josep (1999a), Les primeres “reportationes” de sermons de St. Vicent Ferrer les de Friedrich von Amberg, Fribourg, Cordeliers, ms. 62, "Arxiu de Textos Catalans Antics" 18, pp. 63-155.

Perarnau i Espelt, Josep (1999b), Els manuscrits d'esquemes i de notes de sermons de sant Vicent Ferrer, "Arxiu de Textos Catalans Antics" 18, pp. 157-398.

Perarnau i Espelt, Josep (1999c), Sobre el manuscrit de València, Col·legi del Patriarca, amb sermons de sant Vicent Ferrer, "Arxiu de Textos Catalans Antics" 18, pp. 399-453.

Perarnau i Espelt, Josep (1999d), Algunes consideracions entorn dels tres primers passos dels sermons de sant Vicent Ferrer, "Arxiu de Textos Catalans Antics" 18, pp. 455-477.

Perarnau i Espelt, Josep (1999e), Aportació a un inventari de sermons de sant Vicenç Ferrer: temes bíblics, títols i divisions esquemàtiques, "Arxiu de Textos Catalans Antics" 18, pp. 479-811. 
Pérez Martínez, Lorenzo (1957-1958), Misión apostólica de san Vicente Ferrer en Mallorca (1413-1414), "Studia. Revista mensual de cultura religiosa" 28 pp. 133-158; 29, pp. 1-18 [El mismo texto se publicó como un folleto en Mallorca, s. a.].

Petrucci, Armando (1985a), Minuta, autógrafo, libro d'autore, en Il libro e il testo, Urbino, Università degli Studi di Urbino, pp. 397-414 [Trad. española en Petrucci 1999, pp. 73-91].

Petrucci, Armando (1985b), Scrivere il testo, en La critica del testo. Problemi di metodo ed esperienze di lavoro. Atti del convegno di Lecce, 22-26 ottobre 1984, Roma, Salerno, pp. 209-227.

Petrucci, Armando (1985c), La scrittura del testo, en Asor Rosa, Alberto (ed.), Letteratura italiana, vol. IV: L'interpretazione, Turín, Einaudi, pp. 283-308 [Trad. española en Petrucci 2011, pp. 103-131].

Petrucci, Armando (1985d), Da Francesco da Barberino a Eugenio Montale, en Asor Rosa, Alberto (ed.), Letteratura italiana, vol. IV: L'interpretazione, Turín, Einaudi, pp. 309-310, facs. 1-40 [Traducción española en Petrucci 2011, pp. 133-173].

Petrucci, Armando (1992-1993), Dalla minuta al manoscritto d'autore, en Cavallo, Guglielmo; Leonardi, Claudio; Menestò, Enrico (dirs.), Lo spazio letterario del medioevo. 1 . Il medioevo latino. Vol I: La produzione del testo, Roma, Salerno, pp. 353-372 [Trad. española en Petrucci 2011, pp. 51-67].

Petrucci, Armando (1999), Alfabetismo, escritura, sociedad, Barcelona, Gedisa.

Petrucci, Armando (2011), Libros, escrituras y bibliotecas, ed. Francisco M. Gimeno Blay, Salamanca, Ediciones de la Universidad de Salamanca.

Quetif, Jacques (1719), Scriptores ordinis praedicatorum recensiti notisque historicis et criticis illustrati, Lutetiae Parisiorum, J. B. Christophorum Ballard - Nicolaum Smart.

Riera i Sans, Jaume (2013), L'itinerari peninsular de mestre Vicent Ferrer (1408-1416), en Bellveser, Ricardo (coord.), Els valencians en el compromís de Casp $i$ en el Cisma d'Occident, Valencia, Institució Alfons el Magnànim, pp. 403-457.

Riquer, Martí de; Comas, Antoni; Molas, Joaquim (1984), Història de la literatura catalana, vol. II: Part antiga, por Martí de Riquer, 4. ${ }^{\text {a ed., }}$ Barcelona, Editorial Ariel.

Robles Sierra, Adolfo (1987), Correspondencia de San Vicente Ferrer, "Escritos del Vedat", 17, pp. 173-216 [Reproducido en Robles Sierra 1996, pp. 383-451; las referencias bibliográficas proceden de esta edición]. Robles Sierra, Adolfo (1996), Obras y escritos de san Vicente Ferrer, Valencia, Ayuntamiento. 
Robres, Ramón (1955) ¿Un manuscrito de sermones original autógrafo de san Vicente Ferrer?, "Boletín de la Sociedad Castellonense de Cultura" 31, pp. 239-247.

Rosselló Lliteras, Joan (1987), San Vicente Ferrer: su misión en Mallorca (1413-1414), "Butlletí de la Societat Arqueològica Lul-liana" 43, pp. 71-84.

Sanchis Sivera, José (1999), Estudis d'història cultural, Valencia, Institut Interuniversitari de Filologia Valenciana - Barcelona, Publicacions de l'Abadia de Montserrat, 1999, pp. 205-222.

Scarpatetti, Beat M. von (1983), Katalog der datierten Handschriften in der Schweiz in lateinischer Schrift vom Anfang des Mittelalters bis 1550. II. Die Handschriften der Bibliotheken Bern-Porrentruy, Dietikon Zürich, Urs Graf Verlag.

Steffens, Franz (1910), Paléographie latine, París, Honoré Champion.

Teixidor, José (1999), Vida de san Vicente Ferrer, apóstol de Europa, ed. Alfonso Esponera Cerdán, 2 vols.,Valencia, Ayuntamiento.

Utz Tremp, Kathrin (1995), Ein Dominikaner in Franziskanerkloster. Der Wanderprediger Vinzenz Ferrer und ide Freiburger Waldenser (1404). Zu Codex 62 der Franziskanerbibliothek, en Zur geistigen Welt der Franziskaner im 14. und 15. Jahrhundert: Die Bibliothek des Franziskanerklosters in Freiburg/Schweiz, Friburgo, Universitätsverlag, pp. 81-109 [versión francesa en Memoire dominicaine 7 (1996), pp. 117-137].

Valriu, Caterina; Vibot, Tomàs (2010), Sant Vicenç Ferrer a Mallorca, Pollença, El gall editor - Institut d'Estudis Baleàrics.

Zurita, Jerónimo, Anales de la Corona de Aragón, ed. Ángel Canellas López, Libros undécimo, duodécimo y decimotercero, Zaragoza, Diputación - Institución "Fernando el Católico", 2007.

Fecha de recepción del artículo: julio 2018

Fecha de aceptación y versión final: noviembre 2018 